\title{
Entre el mundo del arte y el mundo del trabajo. Herramientas conceptuales para comprender la dimensión laboral del trabajo artístico
}

0

Karina Mauro

CONICET - Universidad de Buenos Aires - Universidad Nacional de las Artes, Argentina karinamauro@hotmail.com

Fecha de recepción: 19/03/2018. Fecha de aceptación: 03/05/2018.

\begin{abstract}
Resumen
En el presente artículo introduciremos algunas herramientas conceptuales que nos permitan comprender la dimensión laboral del desempeño artístico. En primer lugar, nos centraremos en las características específicas de la actividad realizada por los artistas del espectáculo. En segundo término, analizaremos la organización de la producción en las artes del espectáculo, deteniéndonos en los agentes, circuitos y legislación del sector. Por último, indagaremos en las nociones de plusvalía y capital simbólico, y en las formas de su apropiación en los diversos circuitos, así como en los fenómenos de autopercepción y autoprecarización en el ámbito de los trabajadores de la cultura.
\end{abstract}

\section{Between the Worlds of Art and Work. Conceptual Tools to Understand the Labor Dimension of Artistic Work}

\begin{abstract}
In this paper we will introduce some conceptual elements to understand the labor dimension of artistic performance. First, we will focus on the specific characteristics of the activity developed by performing artists. Secondly, we will analyze the organization of production in performing arts, and we will concentrate on agents, circuits and legislation of the sector. Finally, we will look into the ideas of surplus value and symbolic capital, and into the forms of their appropriation in the diverse circuits, as well as into the phenomena of self-perception and "self-chosen" precarization amongst culture workers.
\end{abstract}

I.

En el seno de una cultura eminentemente logocéntrica, racional y utilitaria como la occidental, el lugar del artista del espectáculo resulta problemático. Esto procede

\section{Palabras clave}

artistas del espectáculo; mundo del trabajo; identidad; relaciones de producción; autoprecarización

Keywords

Performing Artists; Work Studies; Identity; Relations of Production; "Self-Chosen" Precarization 
directamente de la especificidad de su actividad, caracterizada por la exhibición pública del cuerpo y de la acción.

Este carácter conflictivo puede rastrearse ya desde el mundo griego. En su reflexión acerca de la "división de lo sensible" en la sociedad helénica Jacques Rancière (2009) plantea que el mimético ostenta un carácter doble. Esta duplicidad no emana tanto de la ficción o falsedad de las acciones que ejecute ${ }^{1}$, como de dar al principio privado del trabajo un carácter público. En la Grecia clásica, la dualidad del mimético consistía, entonces, en exhibir públicamente su trabajo, actividad fabricadora propia de la oscuridad del mundo privado, y, por lo tanto, necesariamente opuesta a la visibilidad del espacio político. Así, al exhibirse como un trabajador, el mimético cuestionaba, con su sola existencia, esa división de lo sensible en la que se sostenía toda la estructura de la polis. Es por ello que el escenario perturba la división de identidades, actividades y espacios.

Para minimizar dicha perturbación, la exhibición en escena será sometida a un principio que la justifique y/o la legitime, siendo subordinada así a la idea de representación. Esto contribuye a situar a los artistas en una posición subalterna, en tanto su tarea se plantea como la ejecución material de un sentido aportado por una instancia heterónoma al hecho espectacular, sea ésta el texto dramático o la visión del director, el coreógrafo, etc. La actividad de los artistas resulta entonces legitimada en la medida en que se subordine a la representación de un sentido valorado colectivamente.

Esto se observa claramente en la jerarquía interna entre los artistas del espectáculo, en cuya cima se encuentran aquellos cuya actividad posee un respaldo discursivo o textual de algún tipo (fundamentalmente, los actores que representan un texto dramático o los músicos que interpretan una partitura) y en cuya base se hallan los que no cuentan con el mismo (los bailarines, que carecen de una notación universalizada como la musical, y los artistas de variedades). Esta discriminación no sólo es palpable en el posicionamiento de unos y otros ante el público, sino en la legislación, en los convenios colectivos de trabajo y en los conflictos surgidos (o solapados) entre las asociaciones gremiales e inclusive en el seno de cada una de ellas, aspectos sobre los que volveremos más adelante.

Pero además, esta concepción del artista del espectáculo como realizador material de una idea ajena, directamente tributaria del dualismo cartesiano, tiene consecuencias en el terreno estrictamente laboral, porque si lo que prima es el sentido que se representa, el ejecutante (generalmente designado como intérprete) es intercambiable. Se produce entonces, con respecto al resultado del trabajo del artista, al que sería legítimo considerar como una obra de arte en sí misma, una suerte de atribución selectiva, por la cual el sentido representado no le corresponde al mismo, sino al autor, director, guionista o coreógrafo ${ }^{2}$. Lo que se le adjudica al artista, en cambio, serán los aspectos negativos derivados del usufructo de su exhibición pública, lo que se traduce en una insistente condena moral, en su vinculación con la prostitución, con la marginalidad, etc., que podemos identificar a lo largo de la historia.

La condena al usufructo de la actividad artística también proviene del mundo griego, en el que ciertas prácticas, tanto artísticas como deportivas, eran toleradas si y sólo si el ciudadano renunciaba a la utilidad que pudieran reportarle, es decir, si renunciaba a la posibilidad de ganar su sustento mediante la misma ${ }^{3}$. Esta concepción del artista se halla en la base de la visión dominante en el mundo de la cultura y de las artes en nuestra sociedad, en la que se le exige a todo aquel que se desempeña en estas actividades, la renuncia (o la renuncia aparente) al usufructo económico por su trabajo, y su consagración al bien común, es decir, a la transmisión de un mensaje que se proponga elevar culturalmente o emancipar políticamente al público.
1. Más allá de los reparos platónicos al respecto y de la solución aristotélica. Para profundizar en esta temática, ver Mauro, 2011.

2. Esto no sólo actúa en detrimento de las condiciones laborales de los artistas, sino en la desvalorización de poéticas o circuitos de producción íntegros por parte de sectores que ocupan la centralidad del campo cultural, en función de la menor o nula injerencia de la instancia autoral o directorial en dichas producciones. Tal es el caso del teatro popular porteño, cuya desvalorización crónica ha conducido a la pérdida de un patrimonio cultural intangible común. Para profundizar, ver Pellettieri, 2002 y Mauro, 2015.

3. Para profundizar en esta problemática, ver Estiú, 1982. 
Simultáneamente, entonces, opera una acusación a todos aquellos que no renuncian a ganar el sustento mediante su trabajo, generando la consiguiente división entre un nosotros culto y un ellos inculto o rapaz, polarización que en nuestro campo cultural es muy notoria.

La exigencia de subordinar la tarea cultural o artística a fines no económicos subyace en concepciones como la de la vocación, que el sentido común le aplica a los artistas, pero también a los docentes ${ }^{4}$, a los médicos, etc., o la de que el placer que reporta el ejercicio de determinada práctica sustituiría la falta de remuneración (lo cual constituye también una condena implícita al placer). Asimismo, subyace en la idea de que la lógica artística y la lógica del beneficio se excluyen mutuamente y de que el verdadero reconocimiento procede de la primera (Bayardo: 1990). Y por último, se halla implícita también en las políticas culturales y científicas, en tanto que casi todos los sistemas de subsidios a las artes, a la cultura y a la investigación, contemplan insumos y gastos de producción, pero no los honorarios de los trabajadores, quienes no sólo llevan adelante el proyecto subsidiado, sino que además poseen cualidades y saberes específicos que constituyen un valor agregado irremplazable para que la obra o el producto final se realice. ${ }^{5}$

Al tiempo que estas concepciones escamotean la condición de trabajo de ciertas actividades, dos explicaciones quedan sustraídas en las mismas. Por un lado, ¿cómo obtienen su sustento quienes sostienen esta visión del arte? ¿Es posible que un sujeto que no obtenga su sustento por otros medios se dedique al arte? ¿Es deseable?

\section{II.}

Hemos consignado que la especificidad de los artistas del espectáculo radica en la exhibición pública de su cuerpo y de su acción, fundamento de la actividad que es previo e independiente de la existencia de un texto, personaje o sentido a transmitir. Esto implica que su actividad se halla signada por una extrema dependencia de la mirada ajena, al punto que la auténtica tarea del artista consiste en desarrollar recursos para obtener y preservar dicha mirada. Ahora bien, ¿qué implicancias tiene esta definición?

En primer lugar, nos centraremos en los aspectos vinculados a la corporalidad del artista. Existe cierto consenso en incluir a las artes del espectáculo entre las expresiones que constituyen el patrimonio cultural inmaterial de una sociedad. De hecho, así lo plantea la propia UNESCO en sus Directrices para la creación de sistemas nacionales de "Tesoros Humanos Vivos", con el espíritu de promover su preservación a partir del relevamiento y la conservación de los saberes, técnicas y prácticas puestos en juego en la producción de un espectáculo en tanto hecho vivo. No obstante, si bien aquello que realiza el actor o el bailarín no es algo meramente material, tal como subyace en la concepción tradicional del artista del espectáculo como un cuerpo que ilustra una obra ideada por otro, tampoco es completamente intangible. En efecto, frente a aquella concepción tradicional fundada en la separación mente-cuerpo y en la primacía, tan cara a Occidente, de la primera sobre el segundo, el artista del espectáculo evidencia la condición de todo sujeto en tanto "ser encarnado" (Merleau Ponty, 1975). Y lo hace en tanto que la singularidad de su desempeño (ese rasgo único e indecible por el que consigue ser mirado por el espectador, en una relación que en el aquí y ahora de la escena escapa y vuelve superfluo a todo control externo) constituye una acción artística en la que lo físico, lo intelectual y lo afectivo se tornan indiscernibles, conformando un entramado que sólo puede ser capturado deficientemente por el discurso o el sentido, dado que es un acontecimiento.

Es por ello que el artista del espectáculo no es un sujeto que meramente hace algo con su cuerpo, sino que es su cuerpo. Existe por tanto una relación material con su
4. En su investigación sobre el trabajo femenino en torno al 1900 , Rodríguez Durán (2014) sostiene que, en virtud de la "ideología de la domesticidad" y de la separación de las esferas pública y privada, las trabajadoras de la educación eran vistas como una extensión del rol materno en el hogar, por lo que su mayor retribución era de tipo afectivo.

5. Cabe destacar que muchas de las afirmaciones que se realizarán en este estudio acerca de los artistas del espectáculo son aplicables también a los intelectuales y científicos. No obstante lo cual, se evidencia necesario un análisis específico de las condiciones laborales y de las ambiguas construcciones identitarias de estos colectivos 
producción, con su arte, que no se limita sólo a su capacidad de realizar una acción a la que pueda atribuírsele una cualidad artística (aplicar una técnica o metodología en tanto potencia de hacer: decir un parlamento, componer un personaje, sentir una emoción, imitar un acento o un gesto, realizar un movimiento, mostrar una habilidad, etc.), sino que implica también la lisa y llana forma: la forma de su cuerpo y, fundamentalmente, de su rostro (marca asociada a un nombre propio ${ }^{6}$ ). Es en este sentido que la apariencia, la belleza, la atracción o sus contrarios (lo feo, la posibilidad de generar rechazo, etc.), lejos de constituir aspectos superficiales o accesorios del trabajo del artista (tal como lo entiende una visión tradicional del espectáculo que sólo legitima su existencia como subordinado a la transmisión de sentidos), constituyen aspectos específicos y fundamentales del mismo, cuyas implicancias evidentes en el terreno laboral sería erróneo desestimar.

Forman parte de esta condición exhibitoria, por lo tanto, aquellas cuestiones vinculadas a la figura y a la edad, real o aparentada, que conlleva un repertorio posible y/o vedado de roles o personajes a asumir. En la tradicional organización histórica de la actividad en compañías estables de carácter familiar o semi-familiar con un actor a la cabeza, la edad jalonaba una suerte de cursus honorum del artista, es decir, el grado de responsabilidad que el mismo podía ir asumiendo en función de la experiencia acumulada y que determinaba, por lo tanto, su lugar en la jerarquía interna del grupo. Esto se evidencia claramente en el reparto de personajes realizado en función del lugar ocupado por cada artista en la compañía (Sarah Bernhardt, por ejemplo, interpretó al joven Hamlet a pesar de ser una mujer de edad avanzada). Pero además, la compañía requería de obras o textos adecuados para su conformación, es decir, para que todos sus integrantes pudieran desempeñarse en escena. Es así como las obras se realizaban por encargo. Con el avance de la dramaturgia realista y el naturalismo stanislavskiano en el teatro, la verosimilitud se erigió como principal fundamento en la relación actor-personaje y la compañía fue paulatinamente sustituida por un elenco que, bajo las órdenes de un director, pone en escena un texto dramático escrito exclusivamente según el impulso creativo individual de un autor. De este modo, el antiguo cursus honorum quedó desactivado y no pudo ser reemplazado por otro más claro o consensuado: la distribución de roles quedó a cargo del productor, del director o del autor, en función de argumentos ambiguos y discutibles como el talento, la adecuación al personaje, el favor del público o de los medios, etc. Por un lado, la actividad quedó librada al proyecto creador de autores y directores, y/o al proyecto comercial de productores sin tener en cuenta las necesidades de los artistas, lo cual no garantiza la disponibilidad de personajes o roles para los trabajadores de todas las edades y contexturas físicas, o con diversos niveles de experiencia. Conforme avanzó el siglo XX, los textos dramáticos, los guiones y las coreografías se centraron cada vez más en determinado segmento etario, que raramente incluye a los mayores, y en cuerpos sin rasgos de estatura y peso demasiado polarizados. Por otra parte, no existe una cualificación certificada o título habilitante que cuente con una aceptación generalizada como para determinar objetivamente el grado de pericia o experiencia del artista, y mucho menos que ejerza algún tipo de influencia y/o presión en el mercado laboral, en pos de evitar discriminaciones etarias o estéticas. Por consiguiente, la figura y la edad real o aparentada se convierten para el artista del espectáculo en aspectos determinantes de la posibilidad de acceder a un empleo. De este modo, son comunes las intervenciones sobre el cuerpo, tanto para mejorar la figura como para disimular la edad y así ampliar las posibilidades de trabajo. Cabe destacar que estas intervenciones, temporales o definitivas, además de conllevar un riesgo para la salud y también para la imagen, corren por cuenta económica del propio artista. Este es el motivo por el cual no es extraño que las mismas sean objeto de formas no tradicionales de publicidad, como es el caso del canje: tratamientos de belleza, dietas o intervenciones quirúrgicas realizadas en forma gratuita a cambio de la mención del servicio, producto y/o profesional en los medios de comunicación.
6. Para profundizar en esta temática, ver Mauro, 2014 
Algo similar puede afirmarse en el caso del vestuario. Como resabio de la histórica itinerancia de las compañías que, previamente a que el crecimiento de las ciudades propiciara su asentamiento, debían trasladarse en busca de espectadores, el vestuario de los artistas era de su propiedad. Por tal motivo, una de las conquistas laborales del colectivo artístico durante el siglo XX consistió en que el vestuario fuese aportado por la producción del espectáculo (lo que también propicia los canjes por publicidad), aunque en contrapartida los artistas perdieran la propiedad del mismo. Actualmente, el aporte del propio vestuario en formas de producción autogestionadas constituye uno de los índices de la gratuidad y/o precariedad del trabajo artístico en las mismas (aspecto sobre el que volveremos más adelante).

La segunda implicancia del carácter exhibitorio de la actividad artística es, sin lugar a dudas, la competencia por la mirada del público. En efecto, la necesidad constante de obtener el favor de los espectadores se halla en la base de una serie de derivaciones que van desde la inestabilidad laboral crónica hasta el surgimiento de jerarquías internas (cuyo punto máximo es la figura del actor-empresario), y que intervenciones externas (institucionales, sindicales, políticas, éticas, etc.) débilmente pueden paliar. En efecto, también ante la mirada del público, las instituciones de formación o los certificados de cualificación revelan su ineficacia al momento de acreditar la condición de artista de un sujeto, por lo que el favor de los espectadores se distribuye en función de lógicas específicas, en parte susceptibles de manipulación y en parte imponderables.

Al respecto, Mariana Baranchuk (2016) afirma que la escisión entre una élite que goza del favor del público y la gran mayoría de sus colegas constituye una dificultad para lograr una organización colectiva de los artistas:

Por ejemplo, la Asociación Argentina de Actores -mutual, gremial, social- debe ser tolerante con los afiliados que declaran mensualmente al sindicato sólo una pequeña parte de lo que realmente percibe, dado que esa parte es muy superior a lo que puede aportar un actor de teatro organizado en cooperativa en más de un año de actividad ininterrumpida. Más aún, el problema se agrava dado que existen actores y músicos que también son empresarios y contratan colegas, pero que en otras ocasiones son, a su vez, contratados como trabajadores por otros empresarios (Baranchuk, 2016: 99).

Por último, la perturbación generada por el carácter exhibitorio de la actividad propició que a lo largo de la historia hayan hecho su aparición una serie de intermediarios que operan entre el artista y la mirada del espectador, esgrimiendo todo tipo de argumentos para justificar su presencia, ya sean de orden moral, religioso, político y económico, además de estético. Ocuparán dicha posición el autor del texto dramático, el director, el dueño del espacio donde el encuentro entre artista y espectador tiene lugar, el empresario que organiza la actividad, el agente de prensa y los medios de comunicación que la difunden, etc. En dichos agentes nos detendremos a continuación.

III.

¿Cómo está organizada la producción en las artes del espectáculo? Partimos de la premisa de que las únicas instancias estrictamente necesarias e indispensables para que un espectáculo tenga lugar son el artista y el espectador. No obstante, existen diversos agentes que intervienen en la elaboración de un espectáculo y es de las relaciones que establecen entre sí que surgen los diversos modos y circuitos de producción y circulación de las obras. Cada uno de estos circuitos tiene sus características propias, su historia y sus vínculos entre sí. En el caso porteño podemos identificar, a lo largo de las décadas, los circuitos comercial, oficial, independiente y alternativo u off. 
Rubens Bayardo (1990) denomina "modelo ideal" a la forma de producción propia del circuito comercial, organización tradicional de la actividad por ser la de más larga data. Describe dicho modelo a partir del teatro de texto:

El productor compra los derechos de una obra, alquila un teatro, contrata a actores, bailarines, escenógrafos, iluminador, director, etc. pagándoles un sueldo y aportes sociales, costea los elementos necesarios para la puesta en escena, promociona el espectáculo y cumple con los requerimientos administrativos y legales. El empresario de paredes garantiza el buen estado y adecuado funcionamiento de la sala. Por su parte los artistas llevan adelante la puesta en escena [...] Concluida la obra, se la representa frente al público y la crítica, con lo que la "producción" se resarce de sus erogaciones y obtiene los beneficios de su inversión (Bayardo, 1990: 28).

Desde la perspectiva de la relación capital-trabajo, la remuneración por la actividad escénica suele convenirse a través de un contrato temporal que fija un cachet por función o por cantidad de funciones, cuyos mínimos están fijados por categoría en el gremio correspondiente (Baranchuk, 2016). En el caso de las artes del espectáculo, esto se fija a partir del convenio colectivo celebrado oportunamente por la Asociación Argentina de Actores y la Asociación de Promotores Teatrales Argentinos (denominación que ostentaba la institución que nuclea a los empresarios teatrales en 1973, año en que se firma el acuerdo).

Ahora bien, para la empresa productora la única forma de amortiguar los costos de la producción y obtener beneficio es que el espectáculo permanezca en cartel (es decir, que se brinden una cantidad de funciones tal que permita generar ganancias una vez que se recupere la inversión). Es por ello que los grandes espectáculos intentan emular un sistema de producción industrial reproduciendo un mismo prototipo en diversas ciudades del mundo y reduciendo la aleatoriedad de la demanda al extraer el mayor beneficio de un producto que cuenta con el beneplácito del público global. Otra forma de reducir la aleatoriedad de la demanda es apelar a una figura reconocida por los espectadores, por lo que el empresario obtiene ganancias a partir de la utilización del capital simbólico aportado por el artista. Por tal motivo, es usual y comprensible que las primeras figuras suelan pactar un porcentual de lo recaudado que se suma al cachet indicado por convenio. Sin embargo, la posibilidad de reproducción de un espectáculo en vivo es parcial, porque cada función es única e irrepetible. Esto representa un límite claro a la industrialización, a pesar de que un mismo espectador pueda ver varias funciones, ya sea porque el espectáculo es siempre diferente o por el deseo de cercanía con una figura, lo cual promueve la explotación de su apariencia física y su vida privada como forma de publicidad.

Por consiguiente, los tres componentes básicos de la producción comercial de espectáculos son el capital, la sala y el trabajo, categoría que reúne a los artistas (autores, directores, coreógrafos, actores, bailarines) y a aquellos que desempeñan tareas no artísticas, como los técnicos, empleados administrativos, etc.

La instancia empresarial, en tanto dueña de los medios de producción, puede revestir dos categorías: empresario de sala y empresario de compañía o de producción (sin perjuicio de que ambos roles puedan ser ocupados por la misma persona o empresa).

El empresario de sala, conocido también como empresario de paredes, es quien posee una sala teatral y la alquila para la realización de espectáculos. Esto supone una serie de instalaciones conformes a la ley y la prestación de servicios como limpieza y boletería (Bayardo, 1990). Además, la sala puede poseer elementos adicionales como una ubicación geográfica favorable para la mayor circulación de personas o inclusive un público asiduo o habitué, en cuyo caso constituirán un aporte al espectáculo que 
se incluye implícitamente en el precio del alquiler. También puede existir el caso contrario: el de una sala que obtiene reconocimiento por parte del público y el campo cultural en su conjunto (crítica, medios, etc.) a partir de un espectáculo exitoso, lo cual le reporta beneficios publicitarios (y en el largo plazo, económicos), sin implicar que la sala tenga la obligación de reconocerle los mismos al espectáculo (situación que se registra en el circuito comercial, pero más aún en el alternativo). Por otra parte, dado que se alquila, la sala no tiene responsabilidad sobre las condiciones de trabajo de los artistas que en ella se desempeñan. Esto le cabe al empresario de compañía o de producción que es quien aporta el capital, a través de gastos que pueden ser de orden material (alquiler de la sala, escenografía, vestuario, etc.) o inmaterial (derechos de autor, publicidad, etc.). Por último, existe también el empresario de gira, que si bien no produce directamente, asume los riesgos de alquilar la sala y de trasladar el espectáculo a cada provincia o localidad.

Desde 1918, los empresarios se hallan nucleados en la SADET (Sociedad Argentina de Empresarios Teatrales), posteriormente rebautizada Asociación de Promotores Teatrales Argentinos y en la actualidad denominada AADET (Asociación Argentina de Empresarios Teatrales). En 2012, la Asociación encargó la realización del libro Los Productores (Kogan, 2012), en el que se narran las memorias de la institución y se destaca el rol del empresario como aquél que hace posible el espectáculo, atendiendo para ello a muchas y diversas actividades y sectores simultáneamente, desde el estacionamiento de autos hasta la venta electrónica de entradas. A su vez, la publicación reconoce al altísimo nivel de informalidad que caracterizó a la actividad desde sus inicios: oficinas que funcionan en bares, pago a los trabajadores por día o por semana, productores paracaidistas que no conocen la actividad y que el propio medio se encarga de expulsar, etc.

Por otra parte, a la par de su surgimiento los medios de comunicación también fueron ocupando un lugar importante en la producción de espectáculos. En primer término, los medios gráficos fueron el espacio para la difusión y crítica de las obras, constituyéndose en el vehículo privilegiado para el reclamo estético y ético de los intelectuales respecto del rumbo de la escena nacional. En segundo término, con el surgimiento de la radio, el cine y más tarde, la televisión, los medios pasaron a ocupar el lugar más relevante en tanto fuente de trabajo y, por consiguiente, empleadores de artistas. Si bien desde un primer momento esto implicó conflictos y negociaciones por las condiciones laborales de los mismos, durante los últimos años se incorporó a la lucha el reconocimiento de los derechos de autor y derechos conexos, que les caben a los intérpretes de obras literarias y/o musicales. Por último, los medios también son un instrumento para la fabricación, el posicionamiento ante el público e incluso la inducción al fracaso de figuras artísticas, por lo que constituyen un agente de inusitado poder en las relaciones de producción, que influyen aun en otros ámbitos productivos, como el teatral.

El caso de los autores es singular dado que no forman parte de la producción. Se concibe al autor como un sujeto que realiza un trabajo de carácter artístico en soledad y que es dueño del producto que genera y luego administra, postura que ha impedido su asimilación a la categoría de trabajador asalariado. El autor cobra por los derechos de su producto, permite o niega su utilización y vela por la no deformación del mismo (en este sentido, el director actúa como el representante del autor en la puesta en escena, en tanto se constituye como garante del sentido de la misma). Los autores son el sector vinculado con el espectáculo que posee la mayor legitimidad en el campo cultural y que a lo largo de la historia ha marcado mayormente el pulso de la actividad. En efecto, los autores son el primer antecedente en la Argentina de un organismo de gestión colectiva de derechos de propiedad intelectual, la Sociedad Argentina de Autores (actual ARGENTORES) constituida en 1910. De este modo, la 
institución obtuvo el reconocimiento del diez por ciento de la recaudación para sus socios, veinticuatro años antes de la sanción de la Ley 11.723 de Propiedad Intelectual, que apareció en el Boletín Oficial el 30 de septiembre de 1933 (Baranchuk, 2016).

Varios son los puntos a destacar con respecto al Estado (nacional, provincial o municipal) en tanto agente interviniente en la producción de espectáculos. En el caso de la Ciudad de Buenos Aires, el primer rol que el Estado desempeñó en la actividad teatral fue el de censor, velando fundamentalmente por el respeto al decoro escénico. El Estado interviene también como empleador de artistas a través de la escena oficial en tanto parte de una política cultural. En este caso, el surgimiento del circuito teatral oficial, tanto nacional como metropolitano fue tardío y resultó heredero de los lineamientos trazados por el reclamo intelectual de una escena culta (que incluye el teatro de texto, la música académica y la danza clásica), desdeñando las expresiones populares (entre las que se incluyen el denominado género chico y, por supuesto, las variedades). Es así como recién en 1933 se creó el Teatro Nacional de la Comedia, que debutaría tres años después en el Teatro Cervantes, y no será hasta 1944 en que se inicie el viejo proyecto de una sala municipal.

En tanto empleador de artistas, el Estado utiliza mayormente dos modalidades. En el caso de los elencos estables, los trabajadores mantienen con su empleador (nacional, provincial o municipal) una relación salarial de dependencia. Es lo que sucede con la orquesta y el cuerpo de bailarines del Teatro Colón, o lo que sucedía con el Teatro Municipal General San Martín hasta 1989. No obstante, la modalidad más extendida actualmente es la contratación directa de los artistas por parte de la sala oficial, a través de un contrato de locación de servicios que no genera relación de dependencia y que, por lo tanto, se encuentra fuera del alcance del convenio colectivo de trabajo.

También el surgimiento de instituciones oficiales de formación para la actuación fue tardío. Recién en 1925 se abre el Conservatorio Nacional de Música y Declamación,? como desprendimiento de la Escuela de Arte Lírico y Escénico que funcionaba en el Teatro Colón. ${ }^{8}$ Habrá que esperar hasta 1957 para la creación de la Escuela Nacional de Arte Dramático "Antonio Cunill Cabanellas", a su vez como desprendimiento del Conservatorio, y que en 1996 pasará a formar parte del IUNA (Instituto Universitario Nacional del Arte), actual UNA (Universidad Nacional de las Artes). Por su parte, la creación de la Escuela Municipal de Arte Dramático (actual Escuela Metropolitana de Arte Dramático) deberá esperar hasta 1965. Surgida como parte del Instituto Lavardén, la misma alcanza su autonomía en 1974. Cabe destacar que los programas de enseñanza de estas instituciones se confeccionaron en clara oposición a la tradicional forma de adquirir el oficio actoral en el seno de las compañías teatrales. Por otra parte, estas instituciones se restringieron al teatro de texto, no existiendo formación oficial para las variedades (recién a fines del siglo XX y principios del XXI se incorporarán algunas disciplinas circenses a las instituciones existentes). ${ }^{9}$ Como ya mencionamos, no existe relación entre la formación oficial para las artes y el mercado laboral, lo cual queda en evidencia en la ineficacia de los títulos y los certificados de cualificación al momento de postular para un trabajo, incluso en la escena estatal. ${ }^{10}$

En cuanto a la legislación de protección y fomento a la actividad, la intervención del Estado fue singularmente tardía y débil en comparación con la realizada en otras áreas de las artes y la cultura (fundamentalmente las letras y las denominadas bellas artes), y su injerencia fue casi nula en materia laboral (aspecto en el que profundizaremos más adelante en el presente dossier).

Conforme el avance de formas de entretenimiento masivas, los sectores de la producción teatral comercial afectados económicamente, serán los promotores de las leyes de protección aún vigentes, basadas en la exención impositiva y en la preservación de
7. Se registran algunos antecedentes en el efímero intento de Gregorio de Laferrere, quien funda el Conservatorio Lavardén en 1908. En 1913, se emprende la creación de teatros infantiles, tanto por iniciativa municipal como privada. Surgen el Teatro Municipal Infantil (denominado Instituto de Teatro Infantil Lavardén, a partir de 1928), y el Teatro Infantil de Angelina Pagano. Es significativo que la iniciativa municipal se oriente a la formación para la actuación de niños, antes que a la de los adultos con vistas a su profesionalización.

8. Es notable la subordinación de la formación para la actuación a la música académica. Sobre todo en comparación con otras disciplinas, como las artes visuales y las letras, que ostenta un desarrollo autónomo muy anterior.

9. Algo similar sucede con la danza, tal como lo plantea Cadús en "Las condiciones laborales de los/as bailarines/as durante la primera mitad del siglo XX", artículo que forma parte del presente dossier. 10. Con respecto a los certificados de cualificación, uno de los ejemplos más significativos es el de los locutores. Según Mariana Baranchuk (2016) los locutores han esgrimido su identidad laboral mucho más fácil y rápidamente (asumiendo su posicionamiento frente a la empresa emisora contratante), con una temprana institucionalización de su organización gremial y sólidos lazos con el Estado en general. Asimismo, la SAL (Sociedad Argentina de Locutores) ha logrado regular la actividad a partir de una férrea centralización del título habilitante, mediante el Régimen de Habilitación de Locutores. Aunque la autora remarca que la exigencia de habilitación previa para desempeñarse como locutor se halla en dirección opuesta a los estándares internacionales en materia de libertad de expresión. 
los espacios teatrales. Subyace en estos argumentos, la idea de una actividad artística siempre en peligro, que por consiguiente necesita de la eximición, no sólo de obligaciones impositivas, sino también de cargas patronales, lo cual afecta directamente las condiciones laborales y la posibilidad de previsión social de los artistas. Estas ideas refuerzan y a la vez son el resultado de la aceptación, sin cuestionamientos, de la precariedad laboral y la informalidad como aparente principio constitutivo del mundo del arte y de la cultura. Tanto para refrendarlos como para rebatirlos, estos argumentos necesitarían ser confrontados con indicadores oficiales acerca de los recursos económicos generados por la actividad, los cuales son hasta el momento insuficientes.

La exención de impuestos a la actividad teatral surge de la conjetura de que la misma garantizará la concreción de proyectos $y$, por consiguiente, la generación de empleo en el sector. La misma constituyó una reivindicación que los empresarios esgrimieron durante décadas tanto a nivel municipal como nacional, hasta que finalmente se aplicó mediante los Decretos Ley 1251/58 y 6066/58 dictados durante el gobierno de facto de Pedro Eugenio Aramburu y refrendados luego por la Ley 14467, durante el gobierno de Arturo Frondizi (que extiende la vigencia de todo el paquete de decretos leyes dictados entre el 23 de septiembre de 1955 y el 30 de abril de 1958, excepto aquellos que hayan sido expresamente indicados como derogados).

También durante el gobierno de Frondizi se sancionó la Ley 14800/59, que obliga a la construcción de una nueva sala de similares características en el solar donde se hubiera demolido un teatro. Ya a mediados de los años 40, la en ese entonces denominada SADET había realizado solicitadas al gobierno de facto de Edelmiro Julián Farrell debido a su preocupación por la demolición y pérdida de teatros, "problema que crea al arte escénico la constante desaparición de salas destinadas a espectáculos teatrales [...] en los últimos ocho años han desaparecido por lo menos diez salas" (Kogan, 2012: 127). Pero no fue hasta la batalla suscitada para impedir la demolición del Teatro Apolo que se sancionó la ley 14800 . Si bien dicha Ley nunca fue reglamentada (lo cual explica que se hayan producido demoliciones de teatros en varias ciudades del país), en febrero de 2012 la legislatura de la Ciudad Autónoma de Buenos Aires aprobó la Ley 4104 que adecua esa vieja reglamentación a la actualidad, al mantener la obligación de iguales dimensiones de escenario y camarines, pero no en la cantidad de localidades e inclusive permite la subdivisión en salas más pequeñas (Kogan, 2012).

Si bien el campo cultural percibe esta reglamentación como positiva para la actividad teatral, el reconocido empresario Carlos Rottemberg (quien fuera Presidente de la AADET durante diez años hasta su retiro del cargo en 2015) afirma que la misma impide a los propietarios el libre uso de su inmueble para otros fines, lo cual constituye una clara restricción al dominio privado. Por consiguiente, estima que la exención impositiva oficia como una especie de contraprestación, para evitarle al Estado recibir una catarata de juicios por expropiación inversa de las salas privadas repentinamente afectadas (Rottemberg, 2017).

Por último, el 18 de noviembre de 2015 (durante la presidencia de Cristina Fernández de Kirchner) fue promulgada la Ley 27203/15 del Régimen Laboral y Previsional del Actor/Intérprete, más conocida como Ley del Actor, cuyo anteproyecto fuera elaborado por equipos técnicos del Ministerio de Trabajo, Empleo y Seguridad Social, el Ministerio de Cultura, el Ministerio de Desarrollo Social, la ANSES y la AFIP, que trabajaron conjuntamente desde 2005 a partir de una iniciativa de la Asociación Argentina de Actores. El objetivo de la Ley es establecer un marco legal de características especiales para la actividad actoral en todas sus ramas, para que los artistas tengan los mismos derechos que el resto de los trabajadores. De este modo, la Ley atiende a la heterogeneidad en la prestación del servicio del artista, que generalmente es 
discontinuo y para una pluralidad de empleadores, lo que provoca la intermitencia en el empleo y la aleatoriedad en los ingresos. La nueva reglamentación se basa, entonces, en la ratificación de la condición de trabajadores en relación de dependencia de actores e intérpretes y en la cobertura previsional, a través de un cómputo diferencial en el que 120 jornadas efectivas de trabajo, continuas o discontinuas, se consideran como un año de servicios con aportes. Lo que la Ley propiciaría, por ende, es la contratación en regla con aportes por parte del empleado y del empleador.

Si bien la sanción de la Ley fue esgrimida como un triunfo, fundamentalmente por parte del gremio actoral, en las declaraciones de algunas figuras, con desempeño en el ámbito comercial y en los medios, se evidenció en qué medida la informalidad en el sector es vivenciada como la norma. En efecto, la obligación de realizar aportes previsionales se interpretaba como una merma en los salarios. No obstante, fue la AADET la que realizó la mayor embestida contra la Ley del Actor, a través de una solicitada publicada el 23 de noviembre de 2015 , menos de 24 horas después del ballotage en las elecciones presidenciales. Luego de la asunción de la Alianza Cambiemos al mando del Ejecutivo, el 26 de abril de 2016, se reglamentaron sólo 7 de los 19 artículos mediante el decreto presidencial 616/16.

Para caracterizar el comportamiento de las agrupaciones gremiales debemos remitirnos a la Asociación Argentina de Actores, dado que este sindicato es el único del sector que se ha mantenido en actividad de manera ininterrumpida desde 1919, asumiendo la representación de los actores teatrales, cinematográficos y televisivos, pero muchas veces también la de bailarines y artistas de variedades. La AAA no posee sólo un carácter sindical, sino también mutual, brindando asistencia médica a sus afiliados. Desde 1991, la misma se formalizó a través de la constitución de la OSA (Obra Social de Actores), mediante la gestión de aportes diferenciados por parte de un directorio propio (Bayardo, 1997).

Habiéndose constituido en 1919 con 118 socios, para 1992 la AAA contaba con 4967 afiliados. En 2000 se registran 5119, que con la crisis de 2001 bajan a 3769 para escalar a 5235, en 2006. ${ }^{11} \mathrm{Si}$ bien inicialmente el afiliado no perdía su condición de tal, en la actualidad el reglamento exige una cantidad de aportes para mantenerla. ${ }^{12}$ Por lo tanto, es plausible que se registren altos niveles de desocupación entre los afiliados, tal como el que Bayardo (1997) señala para 1997, que ascendía a un 86\%.

Tal como lo señala Mariana Baranchuk (2016), mientras que a lo largo del siglo XX los sindicatos de todo el mundo tendieron a abandonar la antigua organización sindical por oficio para generalizar el sindicato por rama de actividad, los actores hicieron el movimiento inverso. En lugar de ir del gremio de oficio a la representación por rama, su fortaleza radicó en ir de la rama al oficio, acentuando las características artesanales de su profesión por sobre las industriales.

La AAA ha orientado sus esfuerzos a la defensa de las condiciones laborales bajo contratación empresarial, por lo que ha tendido a restringir la condición de trabajador solamente a aquellos artistas que se desempeñan en una relación de dependencia inobjetable. Por consiguiente, ha optado por brindar una representación sólo de tipo nominal ${ }^{13}$ a los afiliados que trabajan en el ámbito autogestivo, sector en el que se desempeña el mayor número de artistas. De este modo, la Asociación Argentina de Actores cuenta con diversos convenios colectivos por rama de actividad firmados con empresarios, la mayoría de los cuales datan de la década del 70. ${ }^{14}$

Por otra parte, el perfil del gremio ha estado marcado por la actuación tradicional, es decir, la interpretación de un texto dramático o guión televisivo, cinematográfico o publicitario. Esto se vislumbra claramente en el Convenio Colectivo de Trabajo de
11. Fuente Ministerio de Trabajo, Cit. en Baranchuk, 2016.

12. Los trabajadores con hasta dos años de afiliación, deben realizar 4 aportes por año; de 3 a 10 años de afiliación, 2 aportes por año; de 11 a 30 años, 1 aporte por año. Aquel afiliado que deba más de 6 cuotas podrá ser dado de baja. Datos extraídos del sitio web www.actores. org.ar el 29 de diciembre de 2017.

13. Lo cual incluye la posibilidad nada desdeñable de proveer de una obra social.

14. Mientras el Convenio Colectivo de Teatro data de 1973, el de Televisión y Cine es de 1975. El de Publicidad, en cambio, es de 1990. 
Teatro, organizado en función del teatro de texto a partir del cual se estipulan condiciones de trabajo, roles, escalafones, sueldos, aportes sindicales, etc. La idea que subyace, por tanto, es la de que el proceso de ensayos y el propio acontecimiento escénico, o sea, los ámbitos fundamentales de intervención actoral, no van a modificar en nada al espectáculo, por lo que los contratos estipulados desde el inicio del proyecto van a resultar adecuados al resultado final. Esto es de difícil aplicación en el teatro en general, pero en particular en el circuito alternativo, cuyas pautas estéticas y organizativas difieren ostensiblemente de este modelo.

En el caso de los bailarines, y a pesar de los esfuerzos desarrollados durante los últimos diez años por diversos colectivos, aún no han logrado formalizar un sindicato propio, siendo representados indistintamente a lo largo de las décadas por la AAA, por la Unión Argentina de Artistas de Variedades, por el SADEM (Sindicato Argentino de Músicos) y por los gremios de empleados estatales nacionales o municipales, en el caso de los integrantes de cuerpos de baile estables. Cabe destacar que esto no contempla aspectos específicos de su actividad, como por ejemplo, la necesidad de jubilación anticipada, de horas extras para calentamiento corporal, de condiciones que debe reunir el espacio de trabajo para evitar lesiones, del tratamiento de las mismas cuando se producen, etc.

El conflicto entre sindicatos por la representación de los bailarines se suscitó muy tempranamente, cuando la Unión Argentina de Artistas de Variedades obtuvo su personería jurídica en 1953. En 1973, la AAA incluye a los bailarines en el convenio colectivo de teatro. Dos años después, el convenio colectivo de la UADAV incorpora a bailarines y a coreógrafos.

Pero, en 1995, la UADAV quiebra y la AAA asume la representación de los bailarines (excepto aquellos con desempeño en casas de tango, que quedan bajo la órbita del SADEM). El conflicto resurge en 2012 cuando la UADAV logra levantar la quiebra con apoyo del Sindicato de Gastronómicos (Sousa, 2015). En 2014, el Ministerio de Trabajo accede a un pedido de la UADAV para realizar paritarias y homologar una escala salarial, aunque la AAA considera que esto no implica el reconocimiento de Variedades como el único representante de dicho colectivo, ni que los bailarines debían regirse sólo por dicho sindicato. La batalla adquiere notoriedad pública cuando la productora Diwan-Fucci decide encuadrar a los bailarines del espectáculo Stravaganza en la UADAV y se mantiene hasta la actualidad.

Además de las dificultades suscitadas por la inexistencia de un sindicato específico, el caso de los bailarines pone en evidencia las jerarquías internas que operan entre los propios artistas en función del circuito y el tipo de espacio en el que se desempeñan, pasando por alto la correspondencia de la tarea específica que realizan. Consultada por el conflicto AAA-UADAV, la secretaria gremial de Actores sostiene que

En un primer momento se entendió que Variedades representaba a los bailarines de los circos, las casas de tango y los varieté. Actores, en cambio, abarcaba a los bailarines de las comedias musicales y los espectáculos teatrales con bailarines. En el caso de los bailarines de revista, eran un constante motivo de disputa (testimonio de Alejandra Rincón, secretaria gremial de AAA al momento de la entrevista realizada por Daniel Sousa, 2015: 1).

De este modo, es un curioso entramado construido en base al género de la obra, al espacio y al circuito de exhibición el que determina la categoría del artista: el bailarín de teatro se acercaría más a un actor que el bailarín que se desempeña en un local de tango o en un circo. Algo similar sucede con los dobles y los extras, quienes no están 
representados por la Asociación Argentina de Actores, sino por el SUTEP (Sindicato Único de Trabajadores del Espectáculo Público y Afines de la República Argentina) (Baranchuk, 2016)

Por otra parte, el surgimiento de los distintos medios de comunicación fue complejizando el trabajo de los sindicatos, que buscaron extender su jurisdicción a los mismos. Mariana Baranchuk (2016) señala que la Organización Internacional del Trabajo promueve la compensación de las deficiencias en las condiciones de empleo de los artistas a través de derechos de propiedad intelectual. En la Argentina operan cinco sociedades de gestión de derechos de autor o de derechos conexos (tanto patrimoniales como morales): ARGENTORES, SADAIC (Sociedad Argentina de Autores y Compositores de Música), AADI-CAPIF (Asociación Argentina de Intérpretes y Cámara Argentina de Productores de Fonogramas y Videogramas), DAC (Directores Argentinos Cinematográficos) y la SAGAI (Sociedad Argentina de Gestión de Actores Intérpretes), que funciona desde $2006 .{ }^{15}$

Como ya mencionamos, ARGENTORES es la sociedad de gestión más antigua. No obstante, si bien desarrolla una extendida función mutual hacia sus afiliados, no controla las condiciones de trabajo de los autores y guionistas en relación de dependencia, dado que no se trata de un sindicato.

En lo que respecta a la SAGAI, se trata de una sociedad civil sin fines de lucro cuya función es representar, recaudar y distribuir los derechos de propiedad intelectual de actores, bailarines y dobladores argentinos y extranjeros en el territorio nacional, por la explotación, utilización, puesta a disposición interactiva o comunicación al público en cualquier forma, de sus interpretaciones fijadas en grabaciones u otros soportes audiovisuales (Baranchuk, 2016). La Sociedad es el resultado de una lucha que el sector venía llevando adelante desde la década del 90, cuando comenzaron a exportarse ficciones televisivas. Si bien la conformación de la SAGAI fue fuertemente resistida por los grandes conglomerados mediáticos, ${ }^{16}$ la existencia de la misma implica la posibilidad para muchos artistas de obtener un medio de subsistencia cuando no tienen trabajo, cuando están retirados o cuando su figura sigue generando plusvalía. Baranchuk sostiene que además, la defensa de los derechos de los intérpretes reporta beneficios adicionales para el conjunto de la sociedad, dado que evita la destrucción de archivos y la consecuente pérdida para el acervo cultural del país (lo cual sucedió con gran parte de la ficción televisiva).

\section{IV.}

Hemos reservado para su tratamiento especial dos regulaciones que consideramos complementarias: la Reglamentación Laboral para Sociedades Accidentales de Trabajo de la Asociación Argentina de Actores y la Ley 24800 de 1997 , más conocida como Ley de Teatro. Es de la combinación de ambas disposiciones que surge y se fortalece el tercer circuito de producción y circulación de espectáculos vigente en la actualidad, el alternativo, que emplea al mayor número de artistas, cuando menos en la Ciudad de Buenos Aires.

La producción teatral autogestionada surge legalmente en 1968, cuando la Asociación Argentina de Actores decide formalizar una modalidad que se venía desarrollando de hecho desde el surgimiento del movimiento de teatro independiente en 1930. En efecto, con la Reglamentación Laboral para Sociedades Accidentales de Trabajo, las autodenominadas cooperativas teatrales fueron incorporadas al régimen laboral vigente como sociedades transitorias. El régimen laboral de dichas sociedades se encuadra en los principios del derecho del trabajo, la ley 14250 de Convenciones Colectivas de
15. La SAGAI fue autorizada para funcionar por la Inspección General de Justicia por Res. № 1125 de fecha 13 de noviembre de 2006 y a través del Decreto 1914/16, firmado el 21 de diciembre de 2006 , se reglamentó tanto el artículo 56 de la Ley 11723 como la actuación de la Sociedad. (Baranchuk, 2016).

16. Que interpusieron una demanda por monopolio que luego fue desestimada por la justicia. En efecto, “El monopolio en la gestión de derechos no puede compararse con un monopolio empresario, ya que es imposible que cada autor se represente a sí mismo o que el usuario sepa en qué sociedad está registrada cada obra" (Baranchuk, 2016: 184) 
Trabajo y las Convenciones Colectivas de Trabajo (CCT) en vigencia (Bayardo: 1990). La sociedad debe registrarse como tal en la AAA y designar un delegado que será el responsable de vincular al grupo con el gremio y con la sala.

Los Fundamentos de la Reglamentación sostienen que:

El presente régimen laboral constituye una experiencia normativa de fundamental importancia para el futuro de la profesión teatral y la consolidación del sistema de producción de espectáculos que consideramos como el más deseable, en beneficio artístico del teatro, de las relaciones de los profesionales entre sí y de los intereses del mismo. La Asociación Argentina de Actores intenta reglamentar una actividad que, de hecho, ha significado un aumento notable de las fuentes de trabajo y de oportunidades para actores y técnicos al mismo tiempo que una clara independencia de criterios que ha significado un aporte esencial para la calidad de los repertorios y de las realizaciones [...] Pero [la AAA] también considera que es su obligación ineludible, como ente gremial y social, vigilar que ningún sistema existente o por existir, haga retroceder o permita transgredir cualquier tipo de conquista lograda a través del tiempo y la lucha de todos los actores. Por ese motivo, el presente régimen establece, en cuanto a los derechos de los integrantes de las sociedades accidentales de trabajo, un paralelismo riguroso con los derechos que el convenio colectivo de trabajo de teatro en vigencia, ampara y obliga a respetar. De ahí que, a medida que las conquistas avancen en futuros convenios, avanzará también el espíritu de protección de derechos del presente reglamento (Cit. en Bayardo, 1990: 36-37). ${ }^{17}$

Acordamos con el análisis realizado por Rubens Bayardo (1990) cuando sostiene que habiendo sido el fracaso económico un factor determinante para la disolución del movimiento de teatro independiente, no queda claro cómo podría atribuírsele a las cooperativas "un aumento notable de las fuentes de trabajo y de oportunidades para actores y técnicos", al tiempo que tampoco resulta sostenible la plena independencia de los actores respecto del Estado y de los empresarios. En el mismo sentido, consideramos que la caracterización de las sociedades accidentales de trabajo como el sistema de producción más deseable indica una clara tensión entre reclamos de carácter ético-estéticos y la generación de recursos económicos para la manutención de los artistas.

Las cooperativas de teatro serían entonces sociedades transitorias, constituidas para un solo proyecto teatral. Las mismas funcionarían con capitales provistos por empresarios y en salas alquiladas, mientras que los integrantes de las cooperativas aportarían su trabajo, aceptando ser remunerados en proporción a los rendimientos del espectáculo y renunciando así, a la relación de dependencia. La idea original era que los miembros de la cooperativa fueran socios de la AAA con poder de decisión y veto para incorporar a otros integrantes no asociados, aunque se prohibía expresamente que los inversores capitalistas formaran parte de la sociedad.

Supuestamente, el sistema le garantizaría al trabajador los mismos derechos que le aseguraba el convenio colectivo de trabajo de teatro, a través de la modalidad de puntaje libre. En la misma, los miembros de la sociedad cobrarían el sueldo mínimo y luego se repartirían el excedente según un sistema de puntos consensuado. Pero existía también otra modalidad, la de puntaje proporcional, en la que no se fijaría sueldo mínimo y todos cobrarían por puntaje, cuyo máximo nunca podría superar el triple del mínimo (sistema conocido como 3 a 1). Mientras las sociedades de puntaje libre deberían contemplar sueldo mínimo, aguinaldo, pago de ensayos, etc., las de puntaje proporcional dejaban abierto un espacio de desprotección a los trabajadores (Bayardo: 1990). No obstante, esta fue la única modalidad que llegó a implementarse,
17. La Reglamentación no se encuentra disponible para la consulta actualmente, ni online ni en papel. 
dado que nunca hubo inversores de capital para el teatro cooperativo. Por consiguiente, las cooperativas de puntaje libre desaparecieron y las sociedades debieron abocarse a autoproducir sus espectáculos, aportando módicos capitales además de trabajo.

En los hechos, entonces, de los gastos consignados anteriormente (de producción, de alquiler de sala y de salarios), la sociedad accidental de trabajo exime del pago de sueldos a sus propios integrantes. Así, "siguiendo un modelo empresarial pero contraponiéndose al asalariamiento, las cooperativas estaban inicialmente destinadas a ser empresas suigeneris" (Bayardo, 1990: 28)

En 1997 se sanciona la Ley $\mathrm{N}^{\circ} 24800$ (Ley de Teatro), merced a la cual se creó el Instituto Nacional de Teatro con filiales en todo el país y un sistema de fomento a la producción mediante subsidios a salas pequeñas y a proyectos gestionados por estas sociedades accidentales de trabajo (cabe destacar que el teatro porteño cuenta además, con los subsidios otorgados por PROTEATRO, organismo creado en 1999 por la Ley $\mathrm{N}^{\circ} 156$ del Gobierno de la Ciudad de Buenos Aires, que también otorga subsidios para salas y proyectos encarados por elencos organizados en cooperativa).

La concepción de la que parte esta legislación es la de brindar apoyo a proyectos teatrales que ofrecen una o dos funciones semanales para pocos espectadores, y en los que la experimentación estética prevalezca por sobre el afán de lucro, cualidad que sería garantizada por el trabajo asociativo de los propios creadores, entendiendo como parte de los mismos a los actores y al director (en efecto, el dramaturgo no suele formar parte de la cooperativa teatral percibiendo el $10 \%$ de la recaudación a través de ARGENTORES). Cabe destacar que tanto la solicitud del subsidio, como el registro de la Sociedad Accidental de Trabajo en la AAA están atados al alquiler de una sala por una cantidad fija de funciones. Esto implica que una cooperativa no puede estar registrada si aún no consiguió un espacio donde presentarse y/o no formalizó un contrato con una sala. Por consiguiente, los grupos que ensayan un proyecto durante un tiempo prolongado (lo cual no es inusual en el circuito alternativo) carecen de entidad alguna para el gremio y para el Estado.

En estrecha vinculación con lo antedicho, es necesario señalar que no existen indicadores ni oficiales ni privados (sindicales, empresariales, etc.) que midan el impacto de la aplicación de esta legislación. No obstante, debemos destacar el trabajo de Alejandro Rozenholc (2015). ${ }^{18}$

Es interesante destacar que en el período 2002-2010, Rozenholc establece un promedio de 708 cooperativas registradas por año en la AAA (a razón de 59 por mes), de las cuales resultaron subsidiadas entre el 9,6\% en el caso del INT y el $31,5 \%$ en el caso de PROTEATRO. ${ }^{19} \mathrm{Si}$ tenemos en cuenta que para 1990, Bayardo consigna la inscripción de 600 sociedades accidentales por año (a razón de 50 por mes), observaremos que, más allá de la significación que el sistema de subsidios alcanza en el imaginario del sector, el impacto real del mismo fue modesto.

Ahora bien, en cuanto a las salas, el porcentaje de subsidios respecto de los espacios registrados es considerablemente mayor, alcanzando el $54 \%$. Según el citado estudio, de las 125 salas registradas entre 2000-2010, el INT otorgó subsidios a 677 (a razón de 67 por año), mientras que PROTEATRO lo hizo a 688 (a razón de 68 anuales). Esto no sólo implica un porcentaje mayor respecto de los subsidios otorgados a proyectos teatrales en cooperativas, sino el apoyo múltiple y reiterado a los espacios. Esto implica que el sistema de subsidios está mayormente orientado al fomento de la apertura y funcionamiento de espacios del circuito teatral alternativo, que al fomento de la producción de espectáculos. De hecho, si tenemos en cuenta que para 1990, Rubens Bayardo consigna 60 salas en el off Corrientes, el propósito de la legislación se ha
18. El mismo incluye un análisis cuantitativo construido a partir de información brindada por los diversos organismos que otorgan subsidios a la actividad teatral en el ámbito porteño, y por la Asociación Argentina de Actores, aunque el propio autor aclara que algunos datos están conservados en forma asistemática e incompleta por dichas instituciones. 19. Los subsidios del FNA se ubican en una posición similar a la del INT, con un $12,6 \%$. 
cumplido, dado que la cantidad de espacios se duplicó. Aunque cabe aclarar que es necesario contar con indicadores adecuados y mayor cantidad de estudios cuantitativos para profundizar este análisis, los datos disponibles arrojan un resultado significativo acerca del espíritu de la Ley.

Consideramos que tanto la citada Reglamentación como la Ley de Teatro se inspiraron y al mismo tiempo avalaron y profundizaron las condiciones de producción establecidas por el teatro independiente, movimiento que desde su surgimiento en 1930 contó con una amplia aceptación en nuestro campo cultural, al punto de que varias de sus premisas se volvieron hegemónicas. En efecto, el circuito alternativo u off se plantea como heredero de los ideales de un teatro con pretensiones artísticas liberadas de las presiones comerciales, de la eliminación desde arriba de jerarquías internas entre los artistas (es decir, una horizontalidad esgrimida desde los propios hacedores del hecho teatral, desdeñando el rol fundamental que juega la mirada del espectador en dicho proceso) y de la independencia del Estado y del mercado. Ahora bien, es indudable que una de las características compartidas por el teatro independiente y el circuito alternativo es el carácter endogámico de su público. En efecto, mientras que el teatro independiente era apoyado fundamentalmente por una burguesía de ideología progresista (aunque su objetivo eran los obreros, sector al que jamás llegó), el público del teatro alternativo está conformado mayoritariamente por otros actores o personas vinculadas de una u otra forma con el quehacer artístico.

No obstante, es necesario establecer algunas diferencias sustanciales, que impiden asimilar al actual circuito alternativo u off con aquel teatro independiente.

En primer término, el teatro alternativo no reniega de los subsidios estatales. En segundo término, mientras que el teatro independiente se basaba en la conformación de grupos estables a lo largo de los años, el teatro alternativo se compone de formaciones transitorias (tal como la propia Reglamentación las caracteriza), permitiendo incluso que un mismo artista participe de varias sociedades de trabajo en forma simultánea. Vinculada con la permanencia de los grupos, la propiedad o alquiler prolongado de una sala era una característica de las agrupaciones independientes (al punto que sala y grupo de percibían como una unidad, tal es el caso del Teatro del Pueblo). Esto se explica por el hecho de que el total de la recaudación era utilizado para financiar el espacio, dado que las agrupaciones independientes no pagaban sueldos o dividendos a sus integrantes (aspecto sobre el que volveremos en el presente dossier) y, tal como hemos mencionado, a partir de 1958 tampoco pagaban impuestos. $^{20}$

Este vínculo grupo-sala no se registra en el circuito alternativo, salvo escasas excepciones: las sociedades accidentales de trabajo realizan un contrato con las salas por una cantidad fija de funciones, que puede renovarse, pero que de ninguna manera implica un alquiler permanente o exclusivo del espacio. ${ }^{21}$

Por último, el crecimiento y la permanencia del circuito han generado una gran diversificación de las propuestas y, sobre todo, de diferentes principios programáticos de los artistas que lo componen, de modo tal que un amplio sector el teatro alternativo repite fórmulas aprobadas por el público en igual medida que lo hace el teatro comercial (entre otras prácticas similares).

Ahora bien, ¿cómo es el proceso productivo autogestionado en el circuito alternativo? ¿Se generan recursos en el mismo? De ser así, ¿cómo se distribuyen?

A casi veinte años de la aplicación de la Ley de Teatro, podemos caracterizar la situación actual como de un vigoroso dinamismo, no sólo merced a la proliferación de
20. A lo que deben sumarse aportes, tal como el de Victoria Ocampo, señalado en Verzero, 2010, o de partidos políticos afines.

21. Tal como mencionamos existen excepciones, algunas de ellas vinculadas de alguna manera con el viejo teatro independiente, como es el caso de Andamio 9o, sala fundada por Alejandra Boero luego de su experiencia en Nuevo Teatro y en La Máscara. Dicha sala realizó su conversión en escuela de teatro (estructurada en un ciclo de varios años y asignaturas) y en sala alternativa que se alquila siguiendo la misma modalidad que el resto de las del circuito. Una estructura similar poseen el Sportivo Teatral y Timbre 4, ésta última administrada por una cooperativa. En el común de los casos el camino es inverso: el espacio surge como sala alternativa y luego se alquila para dar clases como modo de complementar los ingresos 
propuestas, sino también a la aparición de numerosas salas teatrales con menos de 300 localidades, dedicadas exclusivamente al circuito alternativo. Como ya mencionamos, entre 2000 y 2010 se registraron 125 salas teatrales alternativas en la Ciudad de Buenos Aires, mientras que las salas oficiales en la ciudad son siete (cinco pertenecientes al Complejo Teatral de Buenos Aires, a las que se suman el Teatro Nacional Cervantes y el Teatro Colón, aunque éste último dedicado exclusivamente a la música académica y al ballet) y las comerciales, veintidós. ${ }^{22}$

Muchas de estas salas no cuentan con subsidio alguno, por lo que se sostienen con los recursos generados por la propia actividad. Esto se implementa mediante la percepción de un porcentaje de la recaudación o, cuando el mismo no logra cubrir un monto mínimo estipulado, con el cobro de un seguro de sala fijo (que usualmente se calcula en base al monto equivalente a 10 butacas vendidas) que corre por cuenta de la sociedad accidental de trabajo. ${ }^{23}$ Otras fuentes de ingreso de estas salas, cuenten o no con subsidio, son el alquiler del espacio para los ensayos de los proyectos (que corren por cuenta de quienes los integran, generalmente antes de contar con subsi$\operatorname{dio}^{24}$ ), y para el dictado de cursos y talleres de actuación, danza y otras disciplinas vinculadas con las artes del espectáculo.

Una consecuencia de la gran cantidad de propuestas ofrecidas en el circuito es la creciente dificultad que afrontan los proyectos para conseguir disponibilidad a pesar de los numerosos espacios existentes. En primer término, la sala acepta programar las obras que les presentan las sociedades accidentales de trabajo siguiendo exclusivamente su propio proyecto creativo-comercial. Rubens Bayardo señala, en un temprano 1990, que "los empresarios de paredes no comprometen el alquiler de la sala de primera intención, sino que evalúan la rentabilidad de albergar a una u otra cooperativa, a veces hasta último momento" (1990: 29). Agrega que como consecuencia, los actores "van y vienen" hasta que se cristaliza el proyecto, por lo que los contratos que deben ser formalizados ante la AAA no se suscriben con mucha antelación, ni tampoco los contratos con la sala. Este es un aspecto que no ha sido modificado por la implementación de la Ley.

Ahora bien, el poder de aceptación o rechazo por parte de la sala no sólo incluye la línea estética elegida, sino también la cantidad de días de función y los espectáculos que se suceden en una misma jornada. De este modo, dado que por motivos comerciales suele haber varias obras en una misma tarde-noche, son los propios integrantes de la sociedad accidental de trabajo quienes deben acondicionar el espacio en un tiempo que siempre es limitado, dejándolo libre de escenografía y limpio para el próximo grupo, lo cual en los hechos incluye también el sector de camarines, cuando lo hay. Esta asunción de tareas no estrictamente artísticas es un rasgo que proviene directamente del teatro independiente, a pesar de que el circuito alternativo carece de aquellos principios programáticos que la exigían como una forma de militancia hacia los ideales del movimiento.

Por otra parte, en los últimos tiempos puede verificarse la implementación de una extendida estrategia por parte de las salas, que consiste en la rápida rotación de espectáculos cuando los mismos no cubren una cantidad mínima de espectadores, pero también cuando los superan. Esto sucede debido a que el recambio por espectáculos nuevos le ofrece a las salas una recaudación segura, producida por el shock inicial de espectadores familiares y amigos de los miembros de las cooperativas. Dado que el contrato (generalmente por seis funciones) se hace antes del estreno y que luego de las mismas ya hay otra obra pautada, el espectáculo forzosamente baja de cartel (o debe cambiar de día y/u horario) teniendo espectadores o no, lo cual redunda en un perjuicio para la inversión realizada por la sociedad accidental de trabajo. En efecto, como ya hemos mencionado en el caso del teatro comercial, para cubrir los
22. Según los datos aportados por la AADET (Asociación Argentina de Empresarios Teatrales) y PROTEATRO (Rozenholc, 2015).

23. Las salas subsidiadas no pueden percibir este seguro, aunque sí el $30 \%$ de la recaudación.

24. Los subsidios deben solicitarse consignando la fecha prevista para el estreno, por lo que cuando éstos comienzan a gestionarse el proyecto ya se encuentra en su fase de ensayos. 
costos de la producción y obtener ganancias es necesario que la obra sea vista por un gran número de espectadores y eso sólo puede conseguirse dando la mayor cantidad posible de funciones. En este sentido, el teatro alternativo posee ya un límite inicial, que es su vocación minoritaria y la capacidad reducida de las salas. Por consiguiente, si a esto se le suma la poca cantidad de funciones semanales y el período limitado de tiempo en cartel, amortizar los costos y producir ganancia son objetivos inalcanzables.

Este es otro aspecto que no se ha subsanado con la aplicación de la Ley y la inversión realizada por el Estado para promover la apertura de más espacios en el circuito alternativo. En efecto, ya en 1990 Rubens Bayardo afirmaba que los espectáculos autogestionados estaban obligados a cambiar de espacio a los tres meses de estrenar, debido a que la sala ya se había comprometido con otro grupo.

Además de las obligaciones ante el espacio, que se asumen con el monto recaudado mediante la venta de entradas o en su defecto con el aporte personal de los miembros de la sociedad accidental de trabajo, ésta afronta los gastos de producción, que según el espíritu de la legislación, deberían ser solventados con el subsidio obtenido. Esto implica gastos de escenografía, vestuario y difusión, rubro creciente en virtud de la gran cantidad de propuestas que coexisten. Por tal motivo, desde hace casi una década, han surgido más de quince pequeñas agencias de prensa dedicadas exclusivamente a la difusión de proyectos del circuito alternativo, fundamentalmente entre críticos que se desempeñan en sitios virtuales y, en menor medida, en medios masivos escritos y radiales. Estas agencias de prensa perciben un monto fijo, que oscila actualmente entre el $15 \%$ y el $30 \%$ del monto del subsidio otorgado.

Por otra parte, el dinamismo alcanzado por el circuito ha desembocado en una notable profesionalización y especialización de agentes (artistas, salas, técnicos, compañías de prensa, y hasta un sistema de ventas online ${ }^{25}$ ) que desarrollan su actividad exclusivamente en el mismo, por lo que ya no se desempeñan gratuitamente como antaño. Por tal motivo, la cooperativa afronta también en cada función realizada el pago del personal técnico (iluminadores y sonidistas) y de otros artistas que no formen parte de la misma (por ejemplo, los músicos, que suelen cobrar un cachet fijo por sus participaciones).

El crecimiento de las propuestas ha propiciado también la irrupción del rol de productor, anteriormente ausente en el teatro alternativo. A diferencia del teatro comercial, el productor no aporta capital, sino que se especializa en el armado de las carpetas para la solicitud de subsidios, percibiendo un monto fijo por el trámite y/o un porcentaje del subsidio cuando éste es obtenido, lo cual no actúa en perjuicio de su participación como miembro de la cooperativa, cuando el proyecto ya está en marcha.

Llegados a este punto, cabe aclarar que los sistemas de subsidios exigen que un mínimo del 30\% del mismo se destine a los honorarios de los actores. Dicho monto debe depositarse en la AAA, que percibe un $6 \%$ del mismo destinado a la obra social, prestación que sólo es brindada para aquellos miembros de la sociedad accidental de trabajo que están afiliados a la misma. Aquellos que no lo están (ya sea porque no lo desean o porque no llegan a cobrar lo mínimo estipulado para poder afiliarse o para pagar la cantidad de cuotas anuales requeridas para no perder la afiliación) no obtienen beneficio alguno por dicho descuento. ${ }^{26}$

Algo similar ocurre con la recaudación por funciones. La sala le entrega al delegado de la sociedad accidental de trabajo la recaudación neta, previo el descuento del 10\% para ARGENTORES. El delegado retiene el $6 \%$ que debe rendir al sindicato y el resto se reparte. Sin embargo, dado que la sociedad de trabajo es la que gestiona la totalidad de la producción y asume los riesgos ante eventuales pérdidas, sus miembros
25. Se trata del administrado por el sitio Alternativateatral.com. El propio nombre del sitio indica su adscripción al circuito y su surgimiento a la vera del éxito y crecimiento del mismo. En un primer momento, la página se constituyó como ámbito virtual que reunía toda la información y permitía realizar difusión sectorizada (a partir de una importante base de datos, que se fue acrecentando con el tiempo). Transcurridos algunos años, el sitio comenzó a gestionar la venta de entradas, mediante el previo acuerdo con las salas para ofrecer dicho servicio. Cabe destacar que la sociedad accidental de trabajo no tiene injerencia alguna en este acuerdo comercial. 26. La AAA no ejerce otro tipo de representación sindical o ante el Estado de los trabajadores autogestionados, al punto que en el sitio web de dicho gremio (www.actores.org. ar) consta la siguiente aclaración: “Informamos a los compañeros/ compañeras que a partir del 13 de marzo de 2015, en el área de atención a cooperativas, NO SE CONFECCIONARAN, NI IMPRIMIRÁN LAS PLANILLAS DE APORTES, DE HABERES Y/O SUBSIDIOS. Por lo tanto, será obligación del delegado de la cooperativa correspondiente traer confeccionadas e impresas por triplicado las planillas de aportes y/o haberes/ subsidios, de lo contrario no podrán realizar los pagos correspondientes en las cajas. El formato de planillas debe ser solicitado vía e-mail a: cooperativa@actores.org.ar.Pedimos colaboración a los compañeros/as ya que la modificación permite agilizar los trámites, disminuir el tiempo de espera y optimizar el trabajo de nuestros recursos humanos, para una mejor atención en nuestra Asociación Argentina de Actores. NO COMPROMETA AL PERSONAL SOLICITANDO LA CONFECCIÓN DE LAS PLANILLAS." (Consultado el 29 de diciembre de 2017). 
afrontan con la responsabilidad estética y económica que exceda al subsidio obtenido, por lo que estos honorarios son muchas veces reinvertidos. Esto no sólo se realiza a través de la utilización directa del dinero correspondiente a honorarios en gastos de producción, sino también mediante la dedicación en tiempo. En virtud de que uno de los pilares del circuito off o alternativo es la experimentación e innovación estética, los tiempos de ensayo son sobradamente prolongados en comparación con los circuitos oficial y comercial. El motivo principal por el que esto puede instrumentarse es que los ensayos no son pagos.

Otro factor que contribuye a la prolongación del tiempo de ensayo es la disponibilidad horaria reducida de los integrantes del elenco, debido a su desempeño laboral en otras actividades, de las que obtienen su sustento (algunas vinculadas con el mundo actoral en otros medios, como publicidad, cine, teatro comercial, televisión, o con la docencia, o en actividades que no tienen relación alguna con lo artístico). Por tal motivo, son usuales los ensayos nocturnos e inclusive de madrugada, práctica propia del teatro comercial de principios del siglo XX y cuya abolición fue una difícil conquista para los actores sindicalizados, tal como analizaremos en el presente dossier.

Por otra parte, el número de actores por cooperativa se establece en función de la cantidad de personajes estipulado por el texto dramático de base, cuando éste existe, o en función del proyecto estético del que se trate, pautas que establece el director, quien generalmente motoriza el proyecto convocando a los actores. En efecto, se registra en el teatro alternativo una supremacía del director, aunque la misma no se explicita en función de la experimentación estética de la que se vanagloria el circuito (que estaría disminuida si fuera comandada) y de la supuesta horizontalidad aportada por el sesgo independiente del que lejanamente proviene. ${ }^{27}$ Por estos motivos, el porcentaje del subsidio destinado a honorarios tendrá una significación variable según la cantidad de actores que integren la obra.

A partir de la somera caracterización realizada, podemos establecer algunas particularidades respecto al trabajo actoral en el circuito teatral alternativo porteño.

Por un lado, las políticas de fomento a la producción han generado un circuito de gran dinamismo artístico, pero también económico, en tanto han surgido y se mantienen en actividad, espacios, técnicos, profesionales y servicios con dedicación exclusiva en el mismo. No obstante, esta generación de recursos no alcanza a los trabajadores de la actuación y la danza, a pesar de que es su labor la que propicia la existencia del hecho artístico en sí mismo. Hemos visto cómo la creciente profesionalización y diversificación estética dentro del circuito ha derivado en una mayor inversión por parte de las cooperativas en contratación de servicios artísticos y/o de especialistas, lo cual implica el desvío de un alto porcentaje del subsidio (cuando el mismo existe) o de la inversión del grupo. El crecimiento del circuito también ha generado una mayor competencia entre los proyectos para obtener espacios en las salas disponibles, lo cual ha generado una rápida rotación de espectáculos que, de este modo, no llegan a recuperar la inversión o a obtener ganancias para repartir entre los miembros de la cooperativa.

Si durante las décadas del 60 y 70 la modalidad de producción teatral en cooperativa se concibió como el puntapié inicial hacia la profesionalización (a través del pasaje al teatro oficial, comercial, al cine y/o la televisión), en el esquema actual gran parte de los artistas desarrollan la totalidad de su carrera en el circuito alternativo y bajo las condiciones de producción descriptas.

En este punto es necesario aclarar un malentendido terminológico que impera en el campo teatral argentino y que inclusive se reproduce en la normativa, en la
27. Este rasgo tiene componentes éticos y también estéticos que redundan en el privilegio en el circuito de determinadas poéticas, como es el caso del denominado teatro posdramático. Para profundizar sobre el teatro posdramático como poética directorial, ver Mauro, 2013. 
comunicación gremial y en los formularios de registro, y es aquél que equipara a las sociedades accidentales de trabajo con cooperativas, términos que se utilizan indistintamente. Las sociedades accidentales de trabajo no están contempladas por la Ley Nacional de Cooperativas, ${ }^{28}$ por lo que no forman parte del movimiento cooperativo nacional, no están asociadas a la Confederación Cooperativa de la República Argentina (Cooperar) ni a la Alianza Cooperativa Internacional (ACI), ni están contempladas en sus estadísticas. Pero, fundamentalmente, estas sociedades accidentales de trabajo no responden a ninguno de los principios cooperativistas.

En primer lugar, porque no se determinan por los parámetros legales y económicos que rigen el pago de dividendos en las cooperativas de trabajo. Siguiendo a Dante Cracogna (s/f), el asociado utiliza el servicio social (ocupación) y la cooperativa le adelanta un precio provisorio (semejante al que, por ejemplo, anticipa la cooperativa agropecuaria al asociado que entrega su producción a cuenta del precio final). Como no puede predecirse con precisión cual será el resultado del ejercicio, la cooperativa adelanta el precio de mercado vigente en ese momento. En el caso de un trabajador, el mismo consiste en la remuneración prevista para los trabajadores de la misma actividad, la cual se halla establecida en los respectivos convenios colectivos de trabajo. La cooperativa adelanta a los asociados a cuenta del resultado final ese precio provisorio. Cerrado el ejercicio se estará en condiciones de determinar el precio definitivo, una vez conocido el resultado económico.

Para el caso de los artistas, el precio de mercado sería el determinado por el Convenio Colectivo vigente desde el año 1973. En primer lugar, la moderada afluencia de público a este tipo de propuestas impide generar excedentes repartibles que se acerquen a dichos montos, por lo que, de poder realizarse los adelantos (utilizando medios económicos de origen externo), los mismos deberían ser devueltos casi en su totalidad al finalizar la temporada (o la unidad de medida que se considere pertinente aplicar a modo de ejercicio económico, dado que ello no se encuentra estipulado ni por la Ley de Teatro ni por la AAA). Por otra parte, el convenio resulta en gran medida inaplicable para el teatro alternativo dado su extremo apego al teatro tradicional, esto es, a la puesta en escena de un texto dramático previo en manos de un director y con categorías de personajes estipuladas previamente, entre otras disposiciones, lo cual no alcanza a las múltiples variables estéticas y de producción que presenta la escena off.

Otra de las claves del cooperativismo es la formación permanente en los principios cooperativistas, para evitar que los miembros de las cooperativas tomen a la misma como una empresa de la que son clientes. Por último, los asociados a una cooperativa no pueden tener representación sindical ni vínculo con los gremios debido a la inexistencia de empleador. Ninguno de los dos principios se hallan presentes en las agrupaciones analizadas.

Recapitulando, el circuito alternativo no es cooperativo, sino un sistema de autoproducción, con inversiones de capital modestas de sus propios miembros y con muy baja rentabilidad, en el que los artistas asumen el riesgo de invertir y/o conseguir dinero $^{29}$ y trabajo (Bayardo: 1990). Es la contracción de una deuda por parte de los artistas el aspecto que el sistema de subsidios pretendería paliar, cuando menos en parte o simbólicamente.

Además, la situación generada a partir de la implementación de este sistema en el teatro ha funcionado como modelo para las reivindicaciones perseguidas por artistas que trabajan en condiciones de producción aún más precarias que las de los actores, como es el caso de los bailarines. Esto se evidencia en el proyecto de la denominada Ley Nacional de Danza, que, confeccionado según el modelo de la Ley de Teatro, se propone alcanzar los mismos logros generados en el ámbito teatral, sin percibir e intentar prever sus dificultades.
28. Ley 20.337 de 1973 , que suplanta a la Ley 11.388 de 1926 y disposiciones posteriores.
29. Gran parte del trabajo de los artistas en el circuito alternativo pasa a ser entonces conseguir dichos fondos mediante fiestas, rifas o subsidios. 
Esta caracterización permite arribar a una serie de interrogantes: ¿cuál es el motivo por el cual la generación de beneficios económicos no alcanza a mejorar la situación de los trabajadores artistas? ¿En qué medida el trabajo asociativo propicia o impide que esta situación se modifique? ${ }^{30}$ ¿En qué medida las condiciones laborales generadas en el circuito alternativo, que es el que cuenta con la mayor cantidad de trabajadores del espectáculo, repercuten en las condiciones laborales en los circuitos comercial y oficial, e incluso en otros medios, como el cine y la televisión? ¿Es esta situación visible para los propios agentes implicados?

\section{V.}

Llegados a este punto, consideramos necesario analizar qué sector genera la plusvalía en las actividades culturales o artísticas, qué sector se la apropia.

Mariana Baranchuk (2016) analiza la especificidad de la cultura como mercancía y de los modos en que el capital logra producir valor a partir de ella y señala la existencia de distintos sectores cada uno de los cuales tiene sus propias leyes de rentabilización, sus propias modalidades de organización del trabajo, de caracterización de sus productos y contenidos, de organización de la producción, distribución y circulación, de relacionamiento con el Estado, etc.

La autora agrega que la industria cultural es un sector que genera plusvalor pero que entra en contradicción con el funcionamiento del trabajo alienado propio del capitalismo dado que el producto cultural impide el borramiento completo de la personalidad de los trabajadores. Eso se debe a que el trabajo creativo requiere de calificación y de cierto grado de autonomía. La producción cultural, aun pudiendo ser mercantil, conserva ciertas estructuras vinculables con lo artesanal, dado que cada acción es única. Es por ello que, sin negar la tendencia creciente a la subsunción del trabajo creativo al capital, existe una tendencia contraria a mantener las huellas de la autoría. Esta imposibilidad de producir un prototipo serializable escapa a las posibilidades de mecanización y, más allá de las inversiones realizadas, su productividad no crece. Es en la confección del prototipo donde se concentra el trabajo creativo, no apropiable en su totalidad por el capital. ${ }^{31}$

Por todo lo antedicho, Baranchuk advierte que la categoría clásica de obrero industrial asalariado no sirve para dar cuenta de los procesos identitarios que se gestan al interior de las industrias culturales, "dado que no todos los colectivos de trabajadores que en ellas se desempeñan tienen relación de dependencia, muchos participan en el diseño del producto y algunos perciben (o debieran percibir) derechos de autor o conexos como parte complementaria de su remuneración" (Baranchuk. 2016: 30). Propone, en cambio, la concepción de "sujetos laborales ampliados" (31) para, a partir de ahí, pensar la conformación de la autorrepresentación identitaria.

Pero además, es necesario desarrollar herramientas conceptuales para relacionar dos cuestiones supuestamente diversas: la actividad artística en relación de dependencia y la autogestiva. En apariencia, estas dos esferas sólo estarían conectadas por el sintoma, es decir, la precariedad laboral. No obstante, consideramos que debe indagarse en los vínculos y tensiones entre las nociones de plusvalía y capital simbólico, no sólo para identificar a los sectores que detentan los medios de producción en el mundo del arte (los empresarios, los medios o el Estado), sino también con indagar en las jerarquías producidas al interior de la propia actividad artística, inclusive la autogestiva. Uno de los principales problemas radica en la imposibilidad que muestran los colectivos artísticos para llevar la cuestión de las jerarquías y la plusvalía al ámbito del circuito cooperativo, donde supuestamente imperaría la igualdad. Además, debemos poder
30. Bayardo señala que en 1987 la AAA encaró la redacción de una nueva reglamentación de cooperativas, pero que en 1988 la conducción del gremio cambió y el proyecto fue abandonado.
31. Ese exceso no apropiable, constituye un capital simbólico para el actor que acrecienta su nombre propio. 
establecer los vínculos que se suscitan entre la generación de recursos materiales y simbólicos por parte del trabajo de los artistas y los distintos circuitos de producción, para observar cómo el capital simbólico apropiado en un circuito que reporta pocas retribuciones materiales, se convierte en beneficios económicos en otro.

Como ya hemos mencionado, la vocación minoritaria y la capacidad reducida de las salas del circuito alternativo propicia que aún con la máxima afluencia posible de público, los ingresos de boletería sean escasos. Por tal motivo, la única posibilidad de aumentar las ganancias es el pasaje al circuito comercial, en cuyo caso será necesaria la intervención de un empresario, quien se beneficia así de la comercialización de un producto terminado y que incluso puede haber sido realizado con subsidio estatal. Ya en 1990, Bayardo advierte que

Si bien por un lado las cooperativas se han mantenido como forma alternativa a la empresarial, por otro lado han venido a converger con prácticas empresarias de principios por completo extraños a los que fueron su fundamento. Casi el único carácter que conservan es el de ser sociedades transitorias, así como conservan el tinte independentista de origen que las propone como modalidad productiva y opción <<ideológica>> libre de coacciones e intereses empresariales extra artísticos. [Los actores] perseveran en presentar a las cooperativas con su marca de origen: como una opción <<ideológica>> en pro de la libertad creadora y en contra de aquellos intereses -sobre todo económicos- que pudieran escamotearla (1990: 27-29).

Sin embargo, agrega que este sistema no ha podido evitar otras formas a las que caracteriza como "mórbidas", es decir, empresarios que contratan directamente a las figuras y que crean una sociedad accidental de trabajo con los actores de reparto para no cumplir con las condiciones del Convenio Colectivo de Trabajo o temporadas de verano con sueldos mínimos y viáticos, y el resto del salario a porcentaje.

Por otra parte, la horizontalidad esgrimida por el circuito alternativo no ha logrado evitar el surgimiento de jerarquías al interior de la actividad. En efecto, en un sistema de producción artística que se pretende y se enuncia como igualitario entre sus integrantes, generación y apropiación de recursos se hallan en particular tensión. Esto se debe en parte a que, tal como lo señala Bayardo, los miembros de una sociedad accidental de trabajo aportan cosas muy diferentes y de difícil evaluación (y como ejemplo, plantea el caso hipotético de alguien que por relaciones personales consigue un descuento en telas para confeccionar el vestuario). De este modo resulta problemático determinar y adjudicarle valor económico a lo que cada integrante aportó a la cooperativa:

Sin embargo, aunque difícil, no sería imposible establecer equivalencias entre unos y otros aportes, en términos de tiempo insumido por cada uno de ellos, asignándoles un valor en términos monetarios o como fuere. De hecho, en lo que hace a ese trabajo esto no se realiza: ni se asigna un valor a las tareas que entran en juego o a los bienes obtenidos en ellas, ni se busca lograr una igualdad en contribuciones por parte de los miembros (Bayardo, 1990:. 32).

Pero si esto es complejo en el caso del valor material de lo que cada integrante aporta, es imposible en lo que respecta al capital simbólico que se genera y al modo incierto en que se produce su apropiación por parte de los sujetos que intervienen en el hecho artístico. En efecto, la apropiación de este capital simbólico no necesariamente se produce en función de lo que cada uno aportó para la producción, ya sea en términos materiales o inclusive artísticos, sino en función del posicionamiento en el enunciado final (por ejemplo, el actor que más se destaque en la puesta en escena) o por ocupar un rol que ya posee una jerarquía superior de antemano. 
Lo anteriormente expuesto queda explícitamente manifiesto, por ejemplo, en la atribución de autoría de los proyectos a dramaturgos y directores. En efecto, en el caso del teatro alternativo, las figuras del dramaturgo y del director son las que concentran la toma de decisiones (determinar el principio y el fin de un proyecto, así como las directrices estéticas que establecerán la utilización de los recursos) y, al mismo tiempo, son quienes retienen el mayor capital simbólico en su persona, aunque el mismo se haya generado como resultado de una creación colectiva. ${ }^{32}$

Esta generación de prestigio y de legitimación del nombre propio, que es en principio intangible, se convierte no obstante en posibilidades de trabajo en otros circuitos y medios más lucrativos. Es así como en los últimos años se ha registrado el pasaje de emblemáticos directores del circuito alternativo al comercial. En este sentido, podemos apreciar que la producción artística colectiva realizada en cooperativas (muchas veces con subsidios del Estado) brinda a algunos integrantes del grupo que desempeñan funciones jerárquicas, oportunidades de profesionalización en otros circuitos. ${ }^{33}$ Ambas retribuciones están ausentes en el caso de los actores o bailarines. En su caso los beneficios económicos que puede brindar en un circuito comercial el capital simbólico obtenido en el circuito alternativo se registra en muy menor medida, dado que la cantidad de artistas que realizan este pasaje es, en proporción, más acotada.

La apropiación de capital simbólico también influencia el ámbito de la enseñanza, complemento ocupacional y, muchas veces, principal fuente de ingresos de los artistas. En cierto sentido (y en ciertos circuitos) el nombre propio que el artista logre construir constituye un capital simbólico de cara a un posible alumnado, mercado de alta disponibilidad en la Ciudad de Buenos Aires, aunque muy vulnerable a los vaivenes económicos y estacionales. En este sentido, cabe destacar que la enseñanza no institucional de la actuación, la dirección y otras disciplinas teatrales y artísticas en general constituye un campo laboral de absoluta informalidad y que cuenta aún con menos datos estadísticos o indicadores que la producción teatral alternativa.

Podemos identificar, no obstante, una clara complementariedad entre el circuito autogestivo y la formación para la actuación, la dirección y la danza, tanto formal e informal. Esto se debe a factores económicos y simbólicos. Por un lado, quienes deciden ejercer la docencia son artistas y directores que generalmente poseen mayor experiencia en el circuito alternativo y se hallan ligados a sus modos de producción (con condiciones laborales precarias). Por otra parte, opera una fuerte desvalorización hacia formas estéticas vinculadas con el teatro comercial y los medios de comunicación, por lo que sólo se consideran transmisibles ciertas metodologías y otras, no.

Las instituciones de formación (oficiales y privadas, tanto formalizadas como informales) toman como modelo el circuito alternativo y, en menor medida, el circuito oficial que esgrime las mismas pautas estéticas (invisibilizando las condiciones de producción en el mismo). Se enseña a autoproducir espectáculos, mientras los alumnos desconocen las pautas estéticas, económicas y laborales del resto de los circuitos y medios a los que luego, no obstante, intentarán ingresar, siendo las razones esgrimidas explícitamente para dicho sesgo, de orden estético/ético.

De este modo, existe un saber que circula por el circuito autogestivo y que contribuye a su reproducción. El mismo plantea la exigencia de un artista que no se limite al ejercicio de su disciplina, sino que sea capaz de ocupar cualquier rol en un proceso productivo que no se denuncia como económico. Al respecto, Rubens Bayardo señala que

Hay una circulación de este, llamémosle, saber escénico que hace que en alguna medida todos los actores estén en condiciones de participar, si no de la concepción, cuanto menos de la realización de los trabajos escénico no actoral, técnico
32. En algunos casos perciben un porcentaje de la recaudación antes e independientemente de que la cooperativa obtenga ganancias para repartir entre sus miembros, como es el caso de los autores del texto dramático o de la adaptación, que en el teatro alternativo muchas veces es el propio director.

33. Muchas veces, la legitimidad de directores y autores es otorgada por el discurso periodístico o académico, que contribuye así a la consolidación de figuras que luego son contratadas por empresarios e incluso por el Estado. 
y de gestión. Esta pauta de flexibilidad en la ejecución de las tareas contribuye a la concreción del trabajo propuesto merced a los conocimientos y habilidades del propio grupo, a la sustitución -si cupiera- de las personas expertas en una función, a la formación de los actores en una variedad de aspectos apta para posteriores especializaciones. (1990: 30).

Así, esta formación no formal, produce una mano de obra sobrecalificada a la que no se le paga por su conocimiento. Quienes finalmente se benefician con ello son los empresarios de teatro comercial y los medios de comunicación que después contratan a esos artistas. También lo es el Estado, que se beneficia al poder esgrimir una oferta artística prolífica y diversificada. Pero además se benefician las salas, comerciales y alternativas (que construyen su prestigio en el circuito, acceden a subsidios y a un público habitué gracias a la calidad del trabajo de los artistas), los directores (que hacen sus puestas utilizando estos saberes) y los agentes intermediarios (fundamentalmente, las agencias de prensa). Así,

las cooperativas cumplen un importante papel en la reproducción y transformación del campo teatral en su conjunto, al proporcionarle modos de producir las obras, obras, puestas en escena, temas, materiales, modos de percibir, actores y otros especialistas teatrales. La lógica productiva de las cooperativas minimiza sus costos no sólo para sí, sino también para las formas empresariales que terminan captando aquellos productos -obras, actores, etc.- que pueden ingresar en una lógica del beneficio en el caso privado y de difusión cultural en el caso del Estado (Bayardo, 1990: 33).

¿Cuál es la razón por la que esta situación se reproduce? ¿Por qué motivo los artistas no han podido articular una estrategia que supere el mero "malestar" por esta gratuidad del trabajo?

Un aspecto significativo es que los artistas se identifican totalmente con la producción de capital simbólico de su tarea, pero no con la plusvalía que la misma genera y con los conflictos derivados de la lucha por su reivindicación, lo cual los asemejaría a cualquier obrero o empleado. Aquella minoría de actores que gozan del favor del público y que son contratados con asiduidad para proyectos comerciales, obtiene beneficios económicos muy por encima del resto sin necesidad de reivindicarse como trabajadores y negociando sus contratos individualmente. Mientras que aquellos que para subsistir deben complementar su trabajo artístico con otras actividades, se refugian en su condición de artistas, acaso como si el resarcimiento simbólico que reporta esta identidad supliera la falta de retribución económica. Por su part, para el público en general, sólo es un artista profesional aquél que obtiene los medios para su subsistencia mediante su trabajo como tal. En este sentido, concordamos con Bayardo (1997) cuando afirma que la lucha en el seno del teatro no fue solamente entre independientes y empresarios, sino entre actores independientes y actores asalariados.

De esta manera, los modos de producción que suponen la precariedad laboral o la total gratuidad del trabajo artístico, no sólo no son cuestionados, sino que son reafirmados por la actitud de los propios artistas. Esto implica que la problemática laboral de los mismos tiene un fuerte arraigo en la cuestión identitaria y es en ese sentido que deberían operar las asociaciones gremiales, fortaleciendo o generando una identidad laboral allí donde no la hay.

Algo que demuestra la labor de la SAGAI desde 2006 es que las reivindicaciones pueden articularse exitosamente cuando la autopercepción de los artistas como trabajadores es garantizada por relaciones de dependencia claras. Pero esta autopercepción se vuelve dificultosa en los sistemas de producción en los que la generación de recursos es más 
limitada (como el teatro comercial respecto de la televisión) o en los sistemas en los que los recursos son desviados a otros sectores, como en la producción autogestiva. En estos casos, cualquier intento de reivindicación laboral de los artistas colisiona siempre con el argumento de que una mejora salarial o inclusive el pago de cargas sociales o impuestos, pondría en peligro la continuidad de la actividad. Estos argumentos refuerzan la idea de que la precariedad laboral sería un principio constitutivo del arte, al punto que su propia existencia se vería comprometida de no mantenerse dichas condiciones. Sin embargo, esto pesa sólo para los artistas, dado que ni los técnicos, ni los dueños de sala, ni los productores, ni los autores son alcanzados por estas premisas.

En este sentido, todos los agentes vinculados con esta problemática han tenido una actitud similar hacia el reconocimiento de la identidad de los artistas como trabajadores. Esto incluye, por supuesto, a los empresarios y productores, quienes a la hora de negociar los salarios de los artistas que contratan, se benefician de la existencia de una mayoría de actores altamente calificados, desocupados o subocupados y deseosos de ingresar a la escena comercial o a los medios masivos de comunicación, después de años de desempeñarse de manera gratuita en el circuito autogestivo.

Consideramos que la ambigüedad en la identidad de los artistas como trabajadores tiene un fuerte anclaje en la división entre circuitos. Esto se manifiesta en la confusión entre las reivindicaciones de los artistas como trabajadores y las reivindicaciones de otros agentes del sector productivo, como los autores o los empresarios (ya sean de compañía o de sala). Esta tendencia a confundir los intereses de los trabajadores con los de otros componentes del sistema productivo, en favor de "la familia teatral" (González Velazco: 2012) o de un circuito independiente en el que imperaría una supuesta horizontalidad, se ha registrado en numerosas ocasiones a lo largo de la historia (algunas de las cuales serán tratadas en el presente dossier), entre las que podemos citar el conflicto entre empresarios y autores en los años 20, o la lucha contra las clausuras de espacios alternativos post-Cromagnon. Si bien las reivindicaciones de los autores y de las salas son absolutamente legítimas, así como lo es la adhesión de los trabajadores artistas a las mismas, la negación y/o invisibilización de las relaciones de producción al interior del mundo del arte y de la cultura, sobre todo en el ámbito del circuito alternativo, no puede resultar más que perjudicial para quienes ocupan el lugar de la fuerza de trabajo en dicho proceso.

En efecto, tomando el ejemplo de los dueños o administradores de espacios, en innegable que ocupan otro lugar en el proceso productivo, por lo que padecen problemáticas diferentes a las de los artistas y que requieren soluciones y medidas específicas. Esto implica que, de conseguirse estas reivindicaciones para las salas, no necesariamente las mismas benefician o modifican la situación de los trabajadores, algo que se evidencia, por ejemplo, en los resultados del actual sistema de subsidios. Reconocer esta situación no actúa en detrimento del carácter alternativo del circuito, ni de la solidaridad y camaradería inherente al mismo. Si bien sus luchas pueden coincidir en algunos aspectos (como el reclamo ante el Estado en defensa de las iniciativas culturales alternativas o comunitarias), pueden diferir e incluso resultar enfrentados en otros. Por ejemplo, la supervivencia de un espacio escénico no puede conseguirse merced a la seguridad física o a las condiciones laborales dignas de los artistas. El carácter autogestivo no impugna la existencia de relaciones de producción, invisibilización cuyo origen se sitúa en el ideal del teatro independiente (tal como veremos más adelante en el presente dossier). La pertenencia al mismo circuito no significa ocupar el mismo lugar en el proceso productivo, más allá de que se luche contra los mismos enemigos. Tampoco esgrimir o autoadjudicarse un carácter independiente puede implicar estar exento de las obligaciones contraídas al ocupar un rol específico en el proceso productivo y una relación respecto de los usuarios o de los agentes que ocupen otros roles en el mismo. ${ }^{34}$
34. En este sentido, es interesante analizar el caso planteado por Mariana Baranchuk (2016) respecto del rol jugado por la UMI (Unión de Músicos Independientes) ante la reglamentación y puesta en vigencia de la Ley del Ejecutante Musical, № 14597/58 después de 48 años de su promulgación. Baranchuk plantea que el decreto 520/05, debió ser derogado mediante el decreto 636/05, por la fuerte oposición de figuras de renombre, incluso de trayectoria musical progresista. Estos músicos independientes, que también eran contratantes de servicios de otros músicos, rechazaron la aplicación de la Ley. Baranchuk afirma que la Ley intentaba combatir el trabajo en negro entre los músicos ejecutantes, mediante la matriculación y el pago a través del sindicato al igual que lo hace la AAA. Si bien la autora plantea reparos respecto de la matriculación, dado se halla en dirección opuesta a los estándares internacionales en materia de libertad de expresión, agrega que el carácter "independiente" de los artistas contratantes no los eximía de sus obligaciones ante los terceros que les prestaban sus servicios. Por su parte, el SADEM manifestó que la derogación fue impulsada "mediáticamente por un grupo de gente de diversa notoriedad que tiene contratos de locación con entidades oficiales, subsidios, músicos en negro a cargo, bandas propias, sesionistas en estudio, cogestiones con locales para shows en vivo, representantes y cachets artísticos que proteger. Personas a los que la ley perjudica porque les incrementa sus costos como empleadores al legalizar el régimen de trabajo de sus músicos" (Cit. En Baranchuk, 2016: 128, extraído de la página de SADEM 18/2/17). 


\section{Vl.}

Lo expuesto hasta aquí nos conduce a reflexionar acerca del extendido paradigma de las industrias creativas como espacios de producción flexibles, en el que las nociones de libertad y autonomía juegan un rol fundamental para la "precarización de sí" (Lorey, 2006) de los trabajadores.

El modelo de las industrias creativas parte de la aplicación de parámetros económicos a la producción, distribución y consumo de bienes y servicios culturales, en los que la creatividad se presenta como un factor esencial para producir valor económico. Estas ideas, en sí mismas no cuestionables, han decantado en un modelo que irradia a otras áreas del trabajo como forma de flexibilización laboral a partir de la organización por proyecto, en el que se externalizan partes del proceso productivo. En esta organización, los recursos humanos son congregados temporalmente para una única producción y luego dispersados cuando ésta termina (Bulloni Yaquinta, 2009). El trabajador se convirtió entonces en el último eslabón de una red incierta de "subcontratación en cascada" (Cabrera, 2014). Por consiguiente, la precarización laboral, la función polivalente, la tercerización y los contratos de tiempo parcial o acotado, que constituyeron de hecho la manera habitual en que se organizó el trabajo artístico, cultural y en los medios de comunicación (Baranchuk: 2016), pasó a conformar un paradigma explícito y aplicable a otras áreas de la producción y del trabajo, que se esgrime como modelo deseable.

Si bien el sistema por proyectos ha mejorado la eficiencia en algunos sectores de la industria cultural, bajando los costos y permitiendo el ingreso a jóvenes que en las circunstancias anteriores tenían dificultades para iniciarse en el oficio (Baranchuk: 2016), el mismo presenta un riesgo elevado en sus resultados y una amenaza constante de temporadas inactivas, al tiempo que carece de estructuras normativas y garantías que minimicen la probabilidad de fracaso (Cabrera: 2014). De este modo, se le aplican al trabajo los riesgos de la empresa y como resultado de la confusión entre productor y trabajador, la incertidumbre pasa a dominar el trayecto trabajo/remuneración. Asimismo, la organización colectiva en sindicatos se ve debilitada dado que "numerosos puestos de trabajo en relación de dependencia fueron sustituidos por personal bajo contratos de locación de servicios a partir de la irrupción, en las formas productivas, de las llamadas productoras independientes" (Baranchuk, 2016: 166).

Noelia Cabrera (2014) plantea como pilares de este sistema los arreglos informales entre los propios trabajadores y la extrema importancia de los contactos personales. Se trata de una red permanente de contactos sociales gestados a través de repetidas colaboraciones, que ofrece los recursos clave de experiencia, reputación y legitimación. En el seno de una organización flexible y transitoria de la producción y el trabajo, estas cadenas de cooperación repetida permanecen, posibilitando así a los empresarios, disponer de una mano de obra altamente calificada y confiable, por lo que constituye una muestra del rol disciplinador del mercado sobre la fuerza de trabajo.

Cabrera sostiene que pertenecer a estas redes de contacto tiene un costo y una normativa tácita que limita las acciones de sus miembros a riesgo de ser excluidos de sus beneficios. Por consiguiente, las redes son asimétricas, en función de las dependencias que se generan entre aquellos capaces de reclutar y aquellos que desean ser reclutados. Si bien la autora analiza el contexto de los técnicos de cine publicitario, estas observaciones son ampliamente extensibles a los artistas con desempeño en cualquiera de los circuitos de producción y circulación de espectáculos en vivo, así como en los medios de comunicación. Bayardo afirma, por ejemplo, que

Las cooperativas comienzan por autoconvocarse, reuniendo a actores y otros artistas que normalmente ya se conocían. Este conocimiento es casi un prerrequisito 
para contraer una deuda cuya cancelación depende de las inciertas recaudaciones que se obtengan con el espectáculo [...] los artistas ponderan su inclusión en ellas según las relaciones personales puestas en juego. (1990: 29).

Estas redes administran implícitamente y autorregulan varios aspectos de la actividad artística. En primer término, operan en el acceso al sector, apelando a las relaciones personales como modo de reducir la incertidumbre sobre la cualificación profesional (dada la débil injerencia de los títulos expedidos por instituciones de formación y la inexistencia de certificados de cualificación). Pero también continúa influyendo en la continuidad y movilidad, ya sea intrasectorial (por ejemplo, en los ascensos de categoría) o intersectorial (en el pasaje entre medios y circuitos). En efecto, las relaciones interpersonales mitigan la ausencia de un cursus honorum claro y explícito al cual recurrir.

En segundo término, estas relaciones informales actúan como mecanismos de regulación social y disciplinamiento que, además de evitar conflictos ponen límite a los reclamos sindicales. En efecto, más allá de lo que se difunde en los medios como forma de publicidad (peleas entre artistas con el fin de promocionar espectáculos y/o promover figuras), existe un fuerte disciplinamiento interno en pos de generar confianza en un medio que es reducido y en el que los contactos se vuelven recurrentes: "La existencia de pocos medios concentrados hace improbable obtener un nuevo empleo si acaso el trabajador decidiera confrontar con su patronal, es allí cuando aparece la autocensura como un modo de conservar la fuente laboral" (Baranchuk, 2016: 232). Lo mismo puede observarse en el caso de los espectáculos en vivo, en cualquier circuito del que se trate.

Por último, este modo de organización de la producción flexible y precaria con un fuerte peso del autodisciplinamiento grupal y en el que los roles de productor y trabajador se confunden, pone de manifiesto un proceso que se ha dado en llamar precarización autodeterminada o precarización de sí.

Isabell Lorey (2006) plantea que las ideas de autonomía y libertad están constitutivamente conectadas con los modelos hegemónicos de subjetivación de las sociedades capitalistas occidentales que tienden a una precarización que los trabajadores de la cultura se autoimponen:

Lo que nos concierne aquí no es la manera en que las personas en general se ven forzadas a la precarización, sino el hecho de que algunas afirman que, en tanto trabajadoras y trabajadores culturales, han elegido libremente unas condiciones precarias de vida y trabajo. [...] De esta manera, sin embargo, la continuas relaciones de poder y dominación se hacen invisibles y los mecanismos de normalización se naturalizan como decisiones autónomas y autoevidentes de los sujetos. (2006: 12-15).

La autora afirma que se trata de producir las condiciones que permiten convertirse en parte activa de las relaciones políticas y económicas dominantes, para lo que resulta crucial la creencia de que hemos elegido nuestras propias situaciones, tanto vitales como laborales, y de que podemos realizarlas de manera relativamente libre y autónoma. Se privilegia el modelo del empresario de sí como modo de subjetivación burguesa moderna, imperceptiblemente hegemónica y normalizadora, con capacidad para bloquear comportamientos resistentes. Este tipo de relaciones de poder no resultan fáciles de percibir justamente porque vienen de la mano de decisiones propias y libres y, podemos agregar según lo expuesto más arriba, de la pertenencia a un grupo altamente disciplinado que paradójicamente sanciona a la autonomía como positiva.

Merced a este modelo, los trabajadores culturales se orientan de forma persistente a diferenciarse de las condiciones de trabajo normales y a distanciarse de las coacciones, 
medidas disciplinarias y controles que a éstas se asociaban. Se opta por decidir por sí mismo en qué trabajar y con quién, por elegir formas precarias de trabajo y vida en tanto permitirían una mayor libertad y autonomía, precisamente a partir de la organización del tiempo propio y, fundamentalmente, de la autodeterminación:

Con frecuencia, estar bien pagado o bien pagada no era una preocupación, porque la remuneración consistía en disfrutar del trabajo. Lo que preocupaba era poder desarrollar las capacidades propias. Por lo general, la aceptación consciente y voluntaria de condiciones de trabajo precarias venía a ser una expresión del deseo de vivir la separación moderna y patriarcal entre reproducción y trabajo asalariado de una manera diferente a la que permitía la situación de trabajo normal. Sin embargo, son precisamente estas condiciones de vida y trabajo alternativas las que se han convertido, de forma creciente, en las más útiles en términos económicos, puesto que favorecen la flexibilidad que exige el mercado de trabajo (Lorey, 2006: 11)

En este tipo de tareas, el tiempo de trabajo y el tiempo libre no tienen fronteras definidas, el trabajo y el ocio ya no se pueden separar. Los trabajadores culturales invierten el tiempo de trabajo no remunerado en acumular una gran cantidad de saber por el que no se les paga, pero que de forma natural se les exige. Esto no viene impuesto desde fuera, sino que se halla conectado tanto con el deseo como con la adaptación:

Los trabajos "voluntarios", es decir, impagados o escasamente pagados en las industrias culturales o académicas, por ejemplo, se aceptan con muchísima frecuencia como un hecho inamovible, en absoluto se exige algo diferente. Se asume la necesidad de andar a la búsqueda de otros trabajos precarios, menos creativos, con el fin de financiar la producción cultural propia. Este financiamiento forzado, y al mismo tiempo elegido de la creatividad propia, no deja de apoyar y reproducir precisamente esas relaciones sufridas y de las que sin embargo se quiere ser parte. Quienes trabajan de forma creativa, estos precarios y precarias que crean y producen cultura, son sujetos que pueden ser explotados fácilmente ya que soportan permanentemente tales condiciones de vida y trabajo porque creen en su propia libertad y autonomía, por sus fantasías de realizarse. En un contexto neoliberal son explotables hasta el extremo de que el Estado siempre los presenta como figuras modelo (Lorey, 2006: 12-13)

Consideramos que en el caso de los artistas del espectáculo porteños esta subjetividad se halla plenamente instalada y es hegemónica. Nuestro interés en el resto del dossier residirá entonces en indagar en los antecedentes históricos de dicha hegemonía, analizando las discusiones en torno a la producción y el trabajo artístico en los años 20 y el modelo impuesto por el teatro independiente en las décadas posteriores.

\section{VII.}

En el presente artículo hemos analizado en qué medida las características específicas de la actividad realizada por los artistas del espectáculo conllevó una ambigua inserción de los mismos en la sociedad a lo largo de la historia occidental. Durante el último siglo, y en la medida en que la lucha por los derechos individuales y colectivos en las sociedades industriales y/o de masas se articuló a partir de identificaciones laborales, la dificultad de los artistas para configurarse como trabajadores tornó aún más evidentes estas ambigüedades.

Por un lado podemos afirmar que los actores son trabajadores. Dado que estos artistas exhiben públicamente su cuerpo, en tanto presencia, acción y/o mera forma, constituyen la principal fuerza de trabajo en el proceso productivo de un 
espectáculo en vivo y una de las más importantes en aquellos generados y reproducidos en los medios de comunicación. Esto significa que los artistas del espectáculo hacen un trabajo y que deben ser remunerados por ello. Su pertenencia al mundo del arte o de la cultura no los convierte en un colectivo ajeno a las problemáticas de los grupos que obtienen sus medios de subsistencia mediante su trabajo. Sin embargo, esto ha sido sistemáticamente invisibilizado, merced a un movimiento de (auto) separación del resto de los trabajadores, al punto de que los artistas muchas veces no se reconocen como tales, sino como un colectivo que está por encima de las demandas materiales. 35

Pero si, por una parte, observamos una diferenciación con otros trabajadores, al mismo tiempo se realiza un movimiento de asimilación, al incorporar estrategias de lucha que, a pesar de no adecuarse a la especificidad artística, se aplicarán con cierta insistencia. ${ }^{36}$ De este modo, se tornan evidentes las diferencias que la especificidad de la actividad plantea entre los actores y otros trabajadores, fundamentalmente en lo que respecta a la organización entre pares, y a la efectividad de la huelga y la autogestión como forma alternativa de organización de su actividad, aspectos sobre los que la reflexión resulta insoslayable a la hora de consolidar una asociación gremial y revertir las condiciones de gratuidad y precariedad del trabajo.

Tal como hemos analizado en este artículo, la autogestión ha mostrado su inadecuación en la defensa del derecho de los artistas o una especie de adecuación ficticia, como son las sociedades accidentales de trabajo, que el imaginario del sector percibe como cooperativas, basadas fundamentalmente en el trabajo gratuito. Sobre este modelo se han montado las políticas de fomento a la producción de espectáculos y un enorme entramado de agentes y servicios que obtienen sus medios de subsistencia a partir de los escasos recursos generados por la actividad. Pero además, es a partir de las precarias condiciones del circuito alternativo, en el que se desempeñan la mayoría de los actores, que se configuran las condiciones laborales de los otros artistas (bailarines y de variedades), y de los demás circuitos teatrales y medios de comunicación, con el beneficio que ello les reporta a los empresarios y al propio Estado.

Esto muestra la influencia ejercida por una subjetividad autoprecarizante y la dificultad de estos grupos para pensar su propia condición, y a partir de allí plantear demandas específicas, y arribar a estrategias y tácticas de lucha que resulten beneficiosas para sí mismos y quizá también para otros colectivos que presentan las mismas dificultades. Creemos que el origen de esta subjetividad autoprecarizante se encuentra en la historia del campo cultural porteño y sobre ella nos centraremos en el resto del presente dossier. Consideramos que, en este sentido, la teoría y la historia pueden y deben realizar un aporte para definir conceptualmente la compleja identidad laboral de los artistas.
35. En este sentido se replica lo que ocurre con otros grupos como, por ejemplo, los intelectuales. Por ello resultó tan conflictiva como inédita la apelación que desde el primer peronismo se realizó a ambos sectores como trabajadores, tal como lo analizamos en el artículo "Identidades y apelaciones antagónicas II. Los trabajadores del espectáculo entre el modelo militante y el modelo sindicalista (1930 - 1955)", que conforma el presente dossier.

36. Tal como veremos "Identidades y apelaciones antagónicas I. ¿Artistas, productores o trabajadores? (1902-1930)", que conforma el presente dossier. 


\section{Bibliografía}

»Baranchuk, M. (2016). Los trabajadores de los medios y sus organizaciones. Buenos Aires: Patria Grande.

" Bayardo, R. (1990). “Economía de la escena. Las cooperativas de teatro” y "La tradición teatral independiente y las tensiones del asalariamiento". Cuadernos de Teatro, 8, 27-40.

» Bayardo, R. (1997). El teatro “off corrientes": ¿una alternativa estético-cultural?, Tesis de Doctorado.

» Bulloni Yaquinta, M. (2009) “Flexibilización laboral y mecanismos informales de regulación de los mercados de trabajo. Un estudio en la producción cinematográfica argentina" Trabajo y Sociedad. Indagaciones sobre el trabajo, la cultura y las prácticas políticas en sociedades segmentadas, 12, 1-15

»Cabrera, N. (2014). "Regulación del trabajo en mercados laborales transitorios. Reflexiones en torno a las relaciones intepersonales en la producción de cine publicitario argentino". Actas VIII Jornadas de Sociología de la UNLP [en línea] Consultado el 3 de junio de 2017 en <www.jornadassociologia.fahce.unlp.edu.ar>.

" Cracogna, D. (s/f). "La retribución de los trabajadores asociados en las cooperativas de trabajo”, en Legislación del Trabajo, T. XXI, pp. 769-787 [en línea]. Consultado el 22 de noviembre de 2016 en Cooperativas de las Américas. Disponible en <www.aciamericas.coop/La-retribucion-de-los-trabajadores $>$.

»Estiú, E. (1982). “La concepción platónico-aristotélica del arte: técnica e inspiración”. Revista de Filosofía 24, 7-26.

»González Velazco, C. (2012). Gente de teatro: ocio y espectáculos en la Buenos Aires de los años veinte. Buenos Aires: Siglo XXI.

» Kogan, G., C. Ulanovsky, S. Pelayes y M. López (2012). Los Productores. Historias de los empresarios teatrales argentinos de todos los tiempos. Buenos Aires: AADET.

"Lorey, I. (2006). “Gubernamentalidad y precarización de si. Sobre la normalización de los productores y productoras culturales”. EIPCP (Instituto Europeo para Políticas Culturales Progresivas) [en línea]. Consultado el 15 de julio de 2017 en $<$ www.eipcp.net/transversal/1106/lorey/es $>$.

» Mauro, K. (2011). “Alcances y límites de una perspectiva canónica: La Actuación entre las nociones de <<representación >> y de <<interpretación>>”. En Escenarios post-catástrofe. México: Artezblai.

»Mauro, K. (2013). "La Actuación en el Teatro Posdramático Argentino". Revista Brasileira de Estudos da Presença, 3, 669-692.

» Mauro, K. (2014). “Elementos para un análisis teórico de la actuación. Los conceptos de Yo Actor, Técnica de Actuación y Metodología Específica". telondefondo. Revista de Teoría y Crítica Teatral, año X, № 19, julio. Disponible en <www. telonfondo.org $>$.

» Mauro, K. (2015). “La Actuación Popular Porteña como patrimonio cultural intangible". En AAVV, \#PensarLaCulturaPública: apuntes para una cartografía nacional (177-183). Buenos Aires: Ministerio de Cultura de la Nación.

» Merleau Ponty, M. (1975). Fenomenología de la percepción. Barcelona: Península. 
»Pellettieri, O. (Dir.) (2002). Historia del Teatro Argentino en Buenos Aires. Vol. II, Buenos Aires: Galerna.

"Pellettieri, O. (Dir.) (2006). Teatro del Pueblo. Una utopía concretada, Buenos Aires: Galerna.

"Rancière, J. (2009). “La división de lo sensible. Estética y política” [en línea] Consultado el 5 de mayo de 2009 en Mesetas.net

"Rodríguez Durán, A. (2014). “Los sentidos del trabajo femenino en la Argentina del 1900”. En Actas de las VIII Jornadas de Sociología de la UNLP. La Plata: Universidad Nacional de La Plata.

"Rottemberg, C. (2017). "Palabra de productor: Carlos Rottemberg y su mirada sobre la crisis”. Todo Teatro, 29 de abril [en línea] Consultado el 7 de julio de 2017 en <www.todoteatro.com.ar/palabra-de-productor-carlos-rottemberg-ysu-mirada-sobre-la-crisis/>.

»Rozenholc, A. (2015). Análisis de los subsidios públicos otorgados a las cooperativas de teatro y a las salas o espacios teatrales pertenecientes al circuito de producción alternativo de la Ciudad Autónoma de Buenos Aires. Los casos del Fondo Nacional de las Artes, el Instituto Proteatro y el Instituto Nacional del Teatro durante el período 2000-2010, Tesis de Maestría [inédita].

"Sousa, D. (2015). “¿Cuánto ganan los bailarines?”. Balletin Dance. La revista argentina de danza, 22, 247, 10 de enero [en línea] Consultado el 30 de noviembre de 2017 en <www.balletindance.com.ar/index.php?option=com_content\&task $=$ view\&id $=945 \&$ ltemid $=1163>$.

»Verzero, L. (2010). “Leónidas Barletta y el Teatro del Pueblo: problemáticas de la izquierda clásica”. telondefondo. Revista de Teoría y Crítica Teatral, año VI. № 11, julio. Disponible en $<w w w . t e l o n d e f o n d o . o r g>$. 